\title{
Drug- and Behavior-associated Changes in Dopamine-related Electrochemical Signals during Intravenous Cocaine Self- Administration in Rats
}

\author{
Alain Gratton ${ }^{1,2}$ and Roy A. Wise ${ }^{2}$ \\ 'Douglas Hospital Research Center, Department of Psychiatry, McGill University, Verdun, Québec, Canada H4H 1R3 and \\ Center for Studies in Behavioral Neurobiology, Department of Psychology, Concordia University, Montréal, Québec, \\ Canada H3G $1 \mathrm{M} 8$
}

High-speed chronoamperometry was used to determine the moment-to-moment and day-to-day changes in dopaminerelated electrochemical signals in the nucleus accumbens of rats allowed to self-administer cocaine $(0.8 \mathrm{mg} / \mathrm{kg} / \mathrm{injec}$ tion) intravenously. The first, unexpected, cocaine injection caused an abrupt and long-lasting decrease in electrochemical signal. The second and subsequent injections caused shorter decreases in signal that were followed, beginning 23 min after injection, with a return of signal toward the preinjection baseline. Thus, the signal increased just prior to each lever press, peaked at the moment of lever pressing, and decreased for some minutes after each response. Over the first testing session, the phasic fluctuations kept the signal somewhat below the preinjection baseline. On the second and subsequent days, there were large increases in signal following presentation of the light stimulus that marked the onset of drug availability and that was paired with each cocaine injection; this light stimulus had no effect on the first day, prior to drug-light pairings. The first injection of the second and subsequent days caused an additional increase in signal; the magnitude of the increase was comparable to that caused by the initial light stimulus, and the two increases summated to elevate voltammetric signals well above the normal baseline. Subsequent injections caused immediate but short-lived decreases in signal, as were seen on the first day; again, the signal returned to or rose slightly above the preinjection level by the time of the next lever press and injection. No decrease was seen after lever presses when earned injections were occasionally withheld; rather, the signal continued to increase slowly until another lever press was made and a subsequent injection was received. When access to the lever was blocked and the infusion pump was inactivated at the end of self-administration sessions, the animals became agitated and the electrochemical signal in-

Received July 12, 1993; revised Dec. 6, 1993; accepted Dec. 31, 1993.

This work was supported by grants from the Medical Research Council of Canada and the National Institute on Drug Abuse of the United States (DA01720) to R.A.W., from the Natural Sciences and Engineering Research Council of Canada to A.G., and from Fonds pour la Formation de Chercheurs et l'Aide à la Recherche. We thank Dr. Eugene Kiyatkin, who collected and analyzed the data and made important contributions to the manuscript. Nicole Richardson's contribution is gratefully acknowledged.

Correspondence should be addressed to Dr. Alain Gratton, Douglas Hospital Research Center, 6875 LaSalle Boulevard, Verdun, Quẻbec, Canada H4H 1 R3.

Copyright (C) 1994 Society for Neuroscience $0270-6474 / 94 / 144130-17 \$ 05.00 / 0$ creased and remained elevated for 20-40 min before gradually declining toward the original baseline. Thus, the effects of cocaine on DA-associated signals in nucleus accumbens (1) changed dramatically during the development of the selfadministration habit and (2) depended on environmental and behavioral as well as pharmacological factors. In trained animals, cocaine self-administration was accompanied by a tonic elevation of DA-associated signals and by phasic fluctuations time-locked to each cocaine injection.

[Key words: chronoamperometry, nucleus accumbens, dopamine, cocaine, drug self-administration, reinforcement]

The psychomotor stimulants amphetamine and cocaine are strongly habit forming if given by intravenous injection. Intravenous stimulant self-administration in experienced animals is very regular. Responses are usually well spaced, with prolonged periods of seemingly aimless stereotyped behavior between regular, seemingly purposeful instrumental acts. Over the interesting range of the dose-response function, response rate varies inversely with dose per injection (see Wise, 1987). Response rate also varies with reinforcement schedule; with increasing response demands, animals adjust their rate of responding such that they maintain a relatively constant hourly drug intake (Pickens and Thompson, 1971). If a slow intravenous supplement is given during a self-administration session, the animals reduce their rate of lever pressing in efficient compensation (Gerber and Wise, 1989); if drug metabolism is accelerated or retarded, this, too, leads to compensatory changes in drug intake (Dougherty and Pickens, 1974). When animals are tested with different doses per injection, peak drug levels in blood vary considerably but the animals reliably respond when blood levels fall to a constant "trigger point" (Yokel and Pickens, 1973, 1974). For rats, the trigger point is a blood level of close to $0.2 \mu \mathrm{g} / \mathrm{ml}$ in the case of $d$-amphetamine (Yokel and Pickens, 1974).

The controlling factors in stimulant self-administration have been a matter of some speculation. It does not appear that drug intake is limited by incapacitating or aversive side effects of the drugs themselves. Rats are clearly capable of lever pressing in the interval between normal drug responses; they will lever press at very rapid rates - several thousand lever presses per hourif rewarding brain stimulation is available between earned drug injections (Wise et al., 1977). The effects of high blood levels of amphetamine do not appear to be aversive, as monkeys will choose infrequent high doses in preference to more frequent low doses (Iglauer et al., 1976) and rats show no reliable preference 
for one over the other (Yokel, 1987). While drug level in the blood is a good predictor of the time of self-administration (Yokel and Pickens, 1973, 1974), it is presumed that it is drug level somewhere in the brain that is "regulated" (see, e.g., Yokel and Pickens, 1973; Pettit and Justice, 1989).

While the psychomotor stimulants amphetamine and cocaine have actions in each of the major monoamine systems of the brain, their reinforcing or "habit-forming" actions have been largely identified with the mesolimbic and mesocortical dopamine (DA) systems. Whereas dopamine antagonists (Yokel and Wise, 1975, 1976; Risner and Jones, 1976; de Wit and Wise, 1977; Ettenberg et al., 1982) and dopaminergic lesions (Roberts et al., 1977, 1980; Lyness et al., 1979) attenuate or block the rewarding effects of amphetamine and cocaine, noradrenergic antagonists and lesions fail to decrease psychomotor stimulant reward (Yokel and Wise, 1975, 1976; Risner and Jones, 1976; de Wit and Wise, 1977; Roberts et al., 1977). Serotonergic lesions, in fact, appear to enhance the rewarding effects of psychomotor stimulants (Lyness et al., 1981; Lyness and Moore, 1983; Loh and Roberts, 1990).

A good deal is known about the cellular actions of the psychomotor stimulants in the DA system. Amphetamine (Ritz and Kuhar, 1989) and cocaine (Boja et al., 1992) each act at the transporter mechanism (Fisher and Cho, 1979) that plays a role in DA release and controls DA reuptake. Amphetamine elevates extracellular DA levels (Zetterstrom et al., 1983) by three actions: it causes impulse-independent (Westerink et al., 1987; Carboni et al., 1989; Hurd and Ungerstedt, 1989) release of DA, it blocks DA reuptake by dopaminergic nerve terminals (Heikkila et al., 1975), and it inhibits the degrading enzyme monoamine oxidase (Miller et al., 1980). Cocaine also elevates extracellular DA (Church et al., 1987), but apparently by a single mechanism: blockade of DA reuptake. Cocaine is not a DA releaser (Heikkila et al., 1975; McMillan, 1983); indeed, since cocaine decreases DAergic impulse flow (Henry et al., 1989), it should be considered a DA release inhibitor. Nonetheless, its effects on DAergic impulse flow and DA release are minor relative to its uptake-inhibiting action; thus, it causes elevations in extracellular DA that appear to be reliably weaker but of the same order of magnitude as those caused by amphetamine (see, e.g., Di Chiara and Imperato, 1988). Amphetamine, like cocaine, causes inhibition of DAergic impulse flow (Bunney et al., 1973), but this effect is strongly outweighed by its releasing and uptake-inhibiting actions (Zetterstrom et al., 1983; Di Chiara and Imperato, 1988).

Inasmuch as DA receptor agonists like apomorphine (Baxter et al., 1974; Yokel and Wise, 1978; Woolverton et al., 1984), piribedil (Yokel and Wise, 1978; Woolverton et al., 1984), bromocriptine (Woolverton et al., 1984; Wise et al., 1990) and, indeed, DA itself (Guerin et al., 1984) are self-administered, it is tempting to speculate that it is DA levels somewhere in the brain that are regulated during stimulant self-administration. Since DA (Guerin et al., 1984) and amphetamine (Phillips et al., 1981; Hocbel et al., 1983) are sclf-administered into the nucleus accumbens (NAcc) and since NAcc DA depletions (Roberts et al., 1977, 1980; Lyness et al., 1979) and NAcc administration of DA antagonists (Phillips et al., 1983) attenuate cocaine self-administration, it is tempting to speculate that DA levels in NAcc are particularly important. DA levels in frontal cortex may also play a role (Goeders and Smith, 1983; but see Martin-Iversen et al., 1986). Two hypotheses have been advanced. First, it is widely assumed that it is a drug-induced increase in extracellular DA that makes amphetamine and cocaine potent reinforcers (Yokel and Wise, 1975; de Wit and Wise, 1977; Roberts et al., 1977; Wise, 1987; Lyness et al., 1979; Ettenberg et al., 1982; Ritz et al., 1987; Wise and Bozarth, 1987; Wise and Rompré, 1989). Second, it has been proposed that DA depletion (Dackis and Gold, 1985) or some other form of "rebound" suppression of activity in the circuitry mediating the rewarding effects of cocaine (Markou and Koob, 1991) is the biological correlate of cocaine craving. While originally proposed as an explanation of the cocaine craving associated with the days and weeks following a cocaine binge in humans, Markou and Koob (1991) have found that rebound insensitivity of the reward system is evident immediately after animals are taken from a cocaine self-administration session; if DA depletion is the biological correlate of the motivation for cocaine, and if motivation can be inferred from rebound insensitivity of the reward system, then DA depletion should be the triggering event not only for cocaine seeking between binges but also for cocaine-seeking responses within binges.

Recent microdialysis studies have revealed that depressed levels of extracellular DA do indeed accompany withdrawal from chronic cocaine (Parsons et al., 1991; M. W. Robertson et al., 1991; Imperato et al., 1992), morphine (Pothos et al., 1991; Acquas and Di Chiara, 1992), and ethanol (Rosetti et al., 1991). However, the temporal resolution of microdialysis studies is not adequate to determine the fluctuations in DA concentration that are associated with the initiation of responding or with the receipt of an earned injection. Moreover, microdialysis experiments have suggested varying conclusions as to the levels of extracellular DA present during cocaine self-administration. While one group of investigators (Pettit and Justice, $1989,1991)$ has reported that self-administered intravenous cocaine causes elevations in NAcc DA levels, another group has reported that elevated NAcc DA is typical of yoked control animals that are cocaine naive but not of self-administering animals that are cocaine experienced (Hurd et al., 1989, 1990). The present study was designed to explore the potential of in vivo voltammetry to shed further light on these matters. DArelated voltammetric signals (Gerhardt et al., 1984, 1989) were taken at 5 sec intervals throughout six daily cocaine self-administration sessions in order to identify fluctuations of DA during the acquisition and maintenance of an intravenous cocaine self-administration habit.

\section{Materials and Methods}

Subjects. Fourteen male Long-Evans rats (280-480 gm; Charles River, St.-Constant, Quebec), housed individually with free access to food and water, were each implanted under sodium pentobarbital anesthesia (75 $\mathrm{mg} / \mathrm{kg}$, i.p., given $10 \mathrm{~min}$ after a $0.05 \mathrm{mg} / \mathrm{kg}$ s.c. injection of atropine sulfate) with an electrochemical probe (aimed at the $\mathrm{NAcc}$ ), an $\mathrm{Ag} / \mathrm{AgCl}$ reference electrode, and a stainless steel ground wire. The flat skull stereotaxic coordinates for NAcc were $1.6 \mathrm{~mm}$ anterior to bregma, 1.6 $\mathrm{mm}$ lateral and $7.4 \mathrm{~mm}$ ventral to the surface of the cortex. The reference and ground wires were implanted in ipsilateral and contralateral parietal cortex, respectively. Pin connectors soldered to the electrochemical, reference, and ground electrodes were inserted into a miniature plastic strip connector that was secured with acrylic dental cement to six stainless steel screws threaded into the cranium. The animals were also each fitted with a chronic Silastic jugular catheter that was fed under the skin to a length of stainless steel hypodermic tubing embedded in the head assembly. The catheters were flushed daily with heparin (200 USP units in $0.2 \mathrm{ml}$ of saline).

Electrochemical probes. Each electrochemical probe consisted of three $30 \mu \mathrm{m}$ carbon fibers that extended 200-300 $\mu \mathrm{m}$ beyond the tip of a pulled glass capillary tube. The carbon fiber bundle was fixed with a 
Figure 1. Histological reconstructions indicating the location of the exposed carbon fibers of the electrode tips. The tips were found between 1.0 and 1.6 $\mathrm{mm}$ anterior to bregma. $a c$, anterior commissure; $c c$, corpus callosum; $C P u$, caudate-putamen; $l v$, lateral ventricle; $N A C c$, nucleus accumbens; $V P$, ventral pallidum.

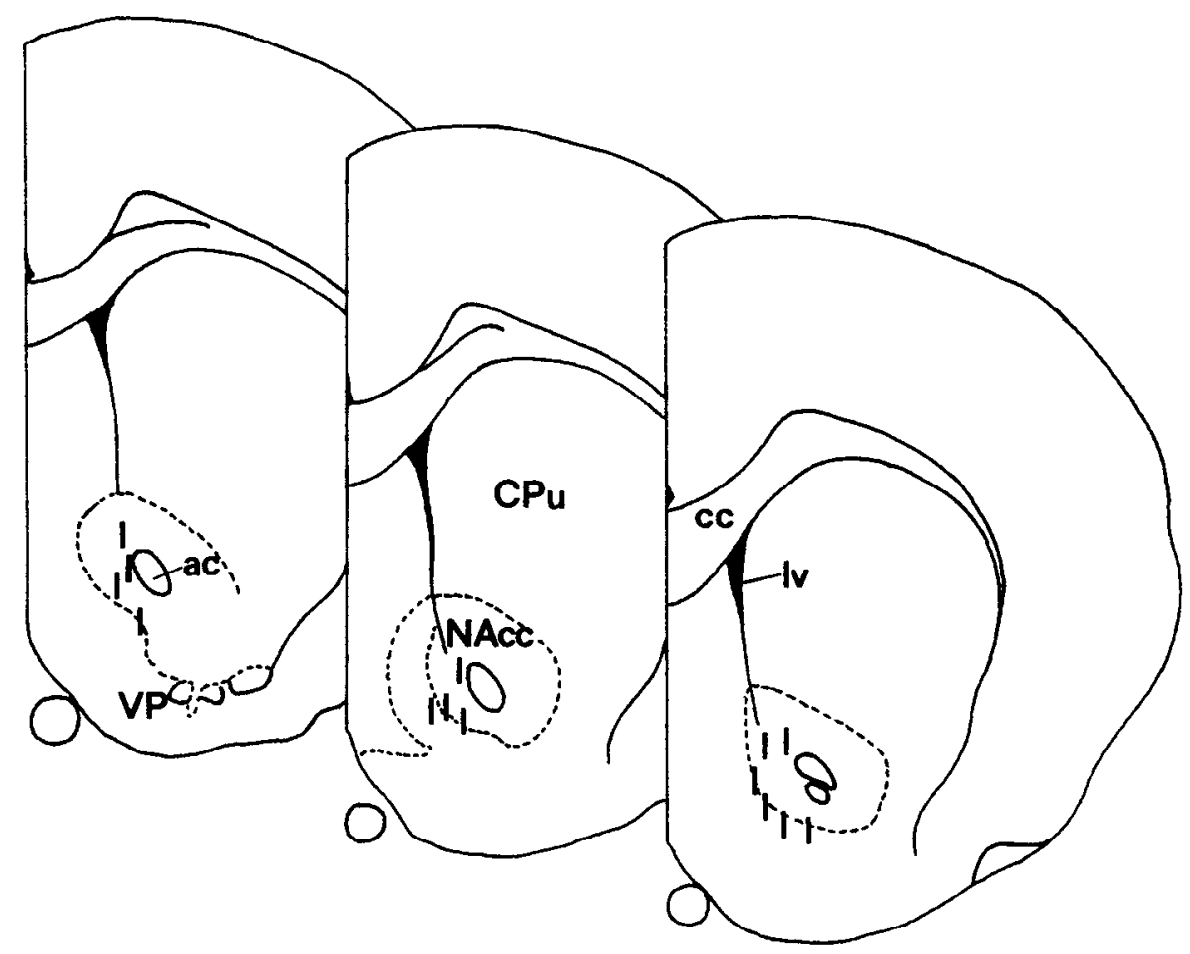

drop of Epoxylite and was coated with Nafion (Aldrich), a polymer that reduces the contribution to the electrochemical signal of anions such as ascorbic acid (AA) and the DA metabolite dihydroxyphenylacetic acid (DOPAC). Prior to implantation, the electrodes were calibrated for their sensitivity to DA and for their selectivity for DA relative to AA. Calibrations were performed in vitro at $25^{\circ} \mathrm{C}$ in $0.1 \mathrm{M}$ phosphate-buffered saline $(\mathrm{pH}=7.4)$ containing a fixed concentration $(250 \mu \mathrm{M})$ of AA to mimic brain extracellular conditions. Only electrodes exhibiting DAto-AA selectivity ratios of at least $1000: 1$ (range $=1000-2000: 1)$ and a linear response $(r>0.997)$ to increasing concentrations of DA were used. Typically, these electrodes exhibit DA-to-DOPAC selectivity ratios of 400-600:1 and detection thresholds for DA of 20-30 nM.

Electrochemical measurements. Electrochemical measurements were performed using a microcomputer-controlled, high-speed chronoamperometric instrument (IVEC-5, Medical Systems Corp., Greenvale, NY). A pulsed oxidation potential of $+0.55 \mathrm{~V}$ (with respect to the reference electrode) was applied to the electrode for $100 \mathrm{msec}$ periods at a rate of $5 \mathrm{~Hz}$. The amplitude of the oxidation current was digitized and integrated over the last $80 \mathrm{msec}$ of each pulse. The digitized current measures were automatically averaged and displayed on a video monitor at $5 \mathrm{sec}$ intervals. The samples of reduction current generated when the potential was returned to resting level $(0.0 \mathrm{~V}$ for $100 \mathrm{msec})$ were digitally integrated and averaged in the same manner and served to help identify the electroactive species undergoing oxidation. With the Nafion-coated carbon fiber electrodes used in the present study and at a sampling rate of $5 \mathrm{~Hz}$, the magnitude of the reduction current for DA is $60-80 \%$ of that of the oxidation current (red : ox ratio $=0.6-0.8$ ). While little or no reduction of AA occurs at the applied and resting potentials used in the present experiments (red : ox ratio $=0$ ), equal increases in oxidation and reduction currents are produced by elevations in DOPAC concentration (red : ox ratio $=1.0$ ); the red : ox ratios for norepinephrine and serotonin are $0.4-0.5$ and $0.1-0.2$, respectively (Gerhardt et al., 1989; Gratton et al., 1989). Thus, the simultaneous monitoring of both the oxidation and reduction currents provides an improved on-line method of differentiating contributions of DA from those of $\mathrm{AA}$ and other monoamines.

Apparatus and procedure. Each animal was acclimatized to the testing environment during two daily sessions prior to surgery. The recording chamber consisted of a wooden box with a glass facade enclosed in a sound-attenuating chamber. A lever connected to a microswitch protruded from one of the walls, $5 \mathrm{~cm}$ above the floor of the chamber; depression of this lever would, in subsequent self-administration sessions, cause intravenous drug delivery.
Drug self-administration and electrochemical recording sessions began $3 \mathrm{~d}$ after surgery. Each animal was connected to the chronoamperometric instrument by a shielded cable and a low-impedence commutator. In order to minimize extraneous electrical interference, the signal was routed through a low current-bias preamplifier that connected directly onto the animal's head assembly. The intravenous catheter was connected to a syringe pump (Razel) by polyethylene tubing and a liquid swivcl incorporated in the commutator. Each lever press caused infusion of $275 \mu \mathrm{g}$ of cocaine in $69 \mu \mathrm{l}$ of sterile physiological saline (fresh each day) over a period of $10 \mathrm{sec}$. Cocaine dose was not corrected for body weight, which varied between animals and fluctuated within animals; on average, the animals lost $15 \%$ of body weight during the course of the experiment. Injection dose thus ranged from 0.69 to $0.98 \mathrm{mg} / \mathrm{kg}$ per infusion. A light $(60 \mathrm{~W})$ inside the experimental chamber was illuminated when the infusion pump was activated.

Immediately before the recording session, the calibration factor for the animal's electrode - the slope of the function relating increases in oxidation current to increases in DA concentration - was entered in the data acquisition software, thus allowing on-line conversion of changes in oxidation current to values equivalent to the changes in DA concentration that would produce an equal signal via the electrode in question. Each animal was placed in the test chamber for 60-90 min while baseline electrochemical signals were recorded; during this period, the operant lever was covered with a glass jar that rendered it visible but not accessible. Once baseline recordings were stable, the record was rezeroed (to correct for the initial downward drift in signal), and 10 min later the chamber light was illuminated for $10 \mathrm{sec}$ and the jar blocking access to the lever was removed; the record was not rezeroed from that point on. Each subsequent lever press was usually (see below) rewarded by a $10 \mathrm{sec}$ cocaine injection, during which the chamber light was illuminated and, unless the animal failed to lever press spontaneously within 30 min, no experimenter-administered injections were given. When an animal failed to lever press within the first $30 \mathrm{~min}$ of a session, one experimenter-administered "priming" injection was given; a priming injection was given to one animal on the first day and one to three animals on each subsequent day. Each animal was allowed to selfadminister cocaine for $120-150 \mathrm{~min}$, and then the lever was again covered with the glass jar; electrochemical measurements were continued for another $40 \mathrm{~min}$. Occasionally, lever presses were intentionally unrewarded, either during or at the end of a self-administration session. Total time of recording was 4-6 hr each day.

After completion of the experiment, the rats were deeply anesthetized with sodium pentobarbital and transcardially perfused with phosphate- 

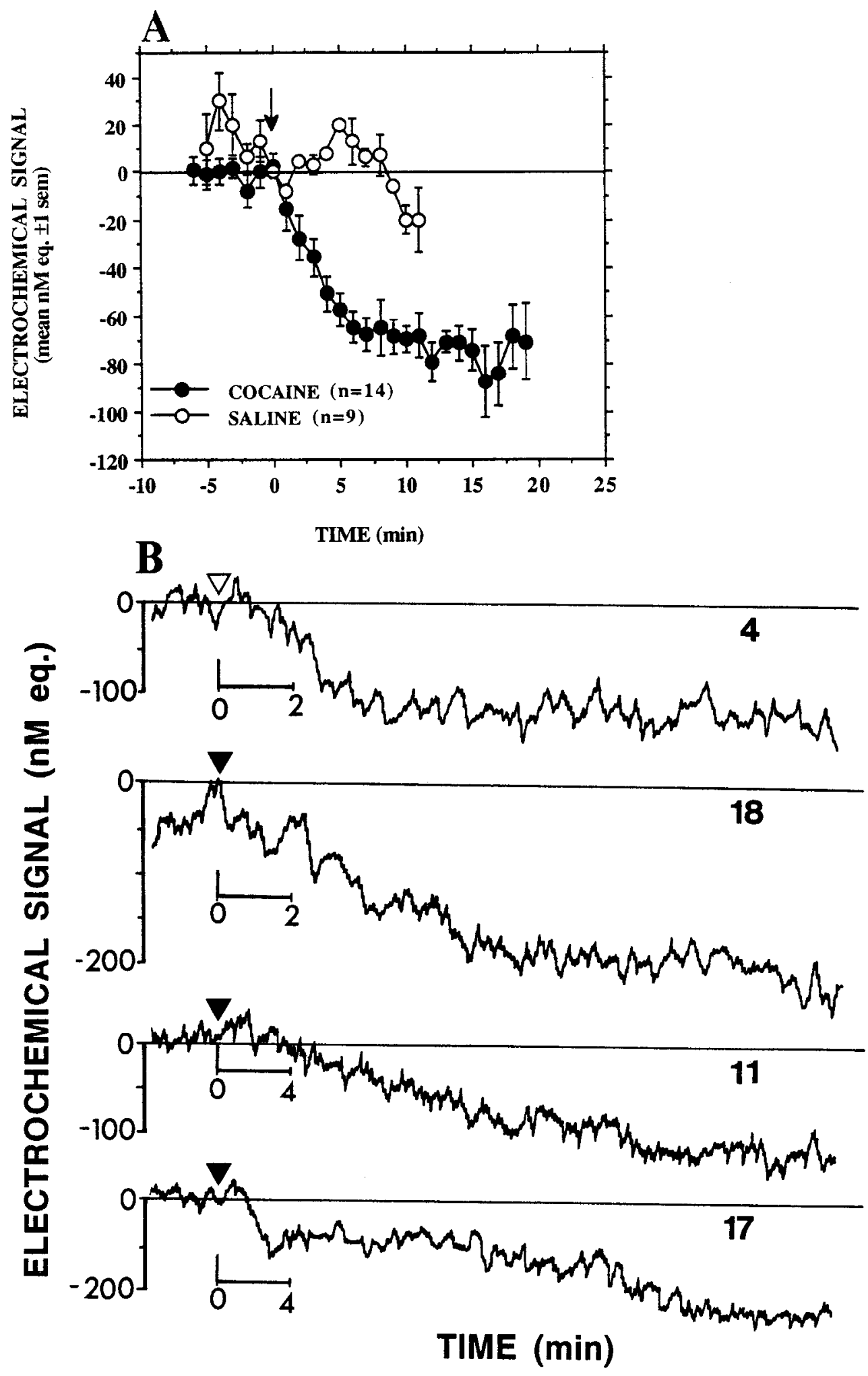

Figure 2. Electrochemical response to the first cocaine injection in naive animals (first session). $A$, Mean change in signal ( \pm 1 SEM) for 14 animals. Mean changes in signal produced by intravenous injections of saline are also shown; the data were obtained from a separate group of three drug-naive animals that each received three experimenter-administered saline injections. $B$, Individual records illustrating the range of variation. In this and all subsequent figures, signal strength is corrected for individual differences in electrode sensitivity and expressed in units (nм eq.) equivalent to the concentration change in DA that would be required to produce the same change in signal during in vitro calibration (nanomolar equivalents). Inverted triangles indicate time of self-administered (solid) and experimenter-administered (open) cocaine injections. Animal identification numbers appear on the right of each record.

buffered saline followed by $10 \%$ formalin. Electrode placements were confirmed from $40 \mu \mathrm{m}$ coronal sections. All data on changes in electrochemical signals were obtained from rats with histologically verified electrode tips within the NAcc (Fig. 1) and with a high positive correlation between within-session changes in oxidation and reduction currents.

Data format. Because the rate of cocaine self-administration varied between animals and between test days, average as well as individual data are presented as changes in electrochemical signal relative to the time of injection (time 0 ). Since the record at time 0 was the point of comparison for changes in electrochemical signal that preceded and followed the injection, it was given a value of 0 .

\section{Results}

Several changes in electrochemical signal were found during the course of the experiment. While marked changes were generally time-locked to cocaine injections and to presentation of the light 

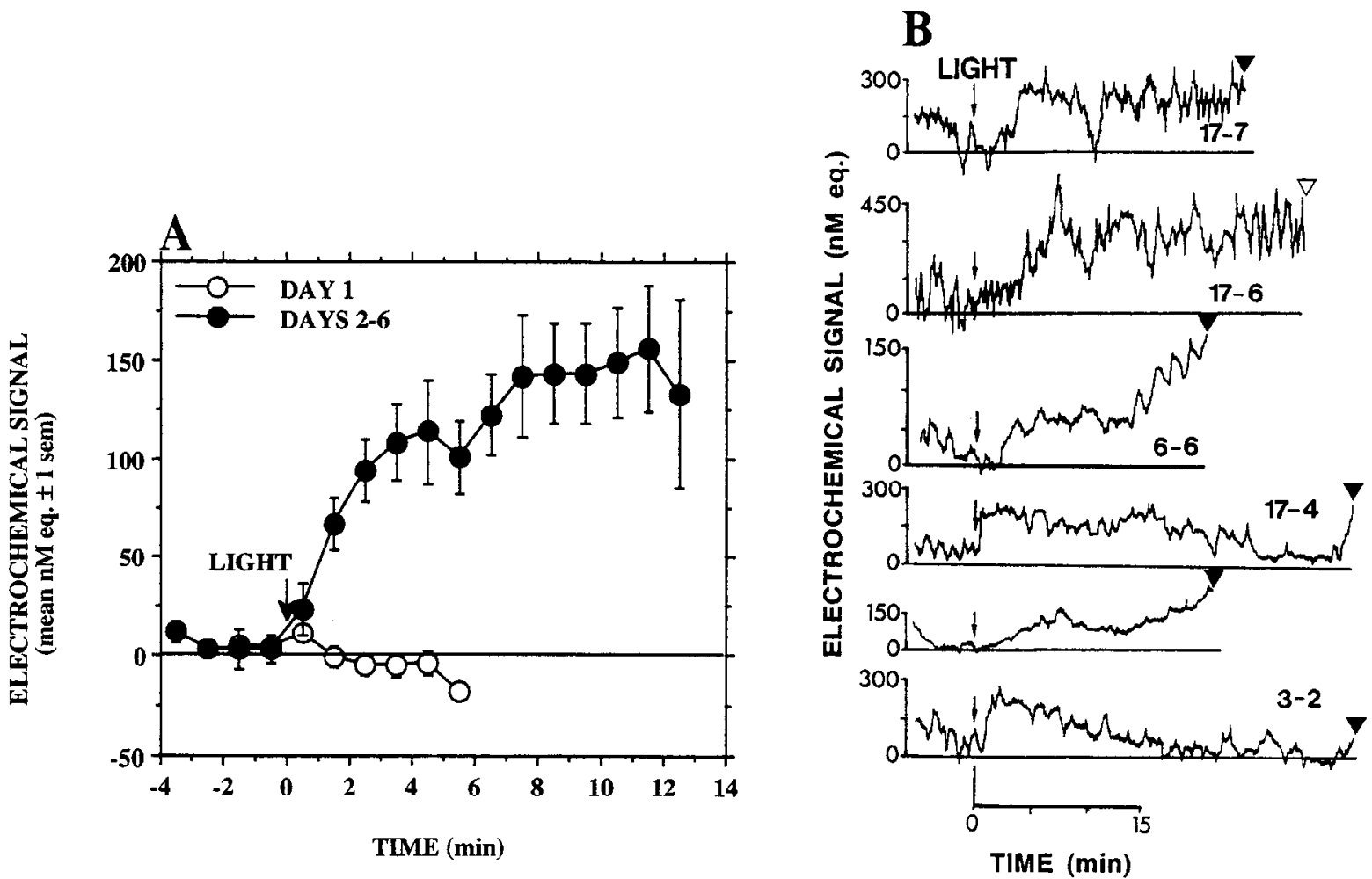

Figure 3. Electrochemical response to the light stimulus. $A$, Mean $( \pm 1$ SEM) change in signal produced by the first (open circles; $n=14)$ and subsequent presentations of the light (solid circles; $n=16$ ). $B$, Individual electrochemical response to the light stimulus recorded during sessions 2-6. Arrows indicate time of light presentation and inverted triangles indicate time of first self-administered (solid) and experimenter-administered (open) injections. In this and subsequent figures, the animal identification number followed (after the dash) by the session number appear on the right of each record.

that was paired with those injections, different electrochemical changes were seen in different phases of the experiment. Electrochemical signals were generally depressed during the first selfadministration session but elevated during subsequent sessions. Signals tended to increase slightly just prior to earned injections and to decrease shortly after most injections. Increases in signal were also associated with presentation of the cocaine-associated light, by the unexpected omission of an "earned" injection, and by the covering of the lever with a glass jar at the end of each self-administration session.

\section{First session}

Thirteen rats made sufficient contact with the lever to trigger an injection during exploration of the test chamber in the first $30 \mathrm{~min}$ of lever access on the first test day; the remaining rat was given an experimenter-administered injection after failing to show interest in the lever. These injections caused behavioral activation (locomotion, rearing, and bursts of grooming) that was obvious for periods of $1-5 \mathrm{~min}$. These initial injections caused long-lasting and profound decreases in electrochemical signal (Fig. $2 A$ ) that accompanied this behavioral activation in each of the 14 rats. The most rapid changes in signal occurred within the first 1 or 2 min after injection (see individual records, Fig. $2 B$ ), but in somc cascs (c.g., animal 11) the change was much more gradual. The mean decrease was equivalent to what would be caused by a $60-75$ nM change in DA concentration; given the relative sensitivity of our electrodes to DA and DOPAC, we estimate that a 30-38 $\mu \mathrm{M}$ change in DOPAC concentration would be required to cause an equivalent change. The change was quite consistent from animal to animal. The periods of recording were limited by the second injection, which occurred as early as $3 \mathrm{~min}$ and as late as $52 \mathrm{~min}$ after the first (mean latency for the second response was $22 \pm 6.2 \mathrm{~min}$ ). Ten animals earned their second injections; four rats that did not show an interest in the lever were given experimenter-administered second injections $45 \mathrm{~min}$ after their first injections. The second and sometimes the third injection drove the signal even lower, but by the fourth injection the signal showed a biphasic change that returned the signal to or slightly above the level recorded just prior to the preceding injection. Thus, over the course of the session, the preinjection level appeared to drift slowly back toward the level of the original baseline taken before the animals were given access to the lever. The sustained depression of the electrochemical signal observed during the first session would prove to distinguish this session from all subsequent sessions.

\section{Second and subsequent sessions}

Each of the 14 animals learned to self-administer cocaine within the first day of testing. The frequency of self-administration varied, between rats and sessions, from 10 to 27 responses/hr, but the pattern of self-administration was generally regular, particularly in the later sessions. In some cases, especially in the initial scssions and early minutes of subsequent sessions, rats made several responses in succession; these multiple responses were usually followed by response-free periods that lasted in proportion to the number of injections in the response "burst." The period of self-administration was accompanied by increased locomotion and stereotyped movements. Total intake of cocaine was relatively stable for individual animals, ranging from 14 to 
$40 \mathrm{mg} / \mathrm{kg}$ in the first $2 \mathrm{hr}$ of each session. There were no significant differences across șessions in the total dose of cocaine earned.

Changes in electrochemical signal were averaged in relation to the moment of lever pressing for the fourth and subsequent injections each day. Data were excluded from this analysis when a lever press preceded or followed in less than $4 \mathrm{~min}$ or when there was movement-related artifact in a record. Since the mean interresponse time was $3.56 \mathrm{~min}$, a large number of records from each animal met the criterion for this analysis.

Light stimulus. The light that signaled onset of each session and was associated with each cocaine injection had no electrochemical consequence prior to being paired with cocaine injections on the first test day; however, from the second day on, it caused increases in electrochemical signal when it was presented without drug at the beginning of each test session (Fig. $3 \mathrm{~A}$ ). While the strongest electrochemical response to the light usually came within the first few minutes, it was not necessarily immediate (see individual records, Fig. $3 B$ ) and in some cases came just prior to the first lever press. These increases were approximately equal in magnitude, but opposite in direction, to the changes associated with the first cocaine injections of the first session. The increase in signals associated with the light occurred in each session except the first; there were no significant changes in the response to the light between the second and sixth sessions. Despite pronounced changes in electrochemical signals, presentation of the light stimulus in cocaine-experienced rats was not always accompanied by any visible changes in behavior. In some cases there seemed to be some degree of locomotor activation.

Initial injections. The first cocaine injection of the second and subsequent days caused similar behavioral but very different electrochemical consequences to the initial injection on the first day. Rather than the clear depressions of electrochemical signal, the first daily injections of the second and subsequent days caused increases in electrochemical signal (Fig. 4) that were approximately equal in magnitude, opposite in direction, and somewhat more rapid in onset than the depressions seen on the first day. Whether the first injections of the second and subsequent days were administered by the experimenter or sclf-administered, they caused essentially the same level of increase. The increases were approximately equal in magnitude to the increases caused by the light stimulus that preceded them; the response to the first injection summated with the response to the light stimulus, thus elevating the electrochemical signal to a plateau that was generally sustained for the rest of the session.

Subsequent injections. The mean changes in electrochemical signal associated with subsequent self-administered injections $(n=285)$ are shown in Figure $5 A$. Individual mean changes for four representative animals are shown in Figure $5 B$, and examples of individual records are shown in Figure 6. Decreases in signal reliably followed each self-administered injection from the fourth injection onward (Fig. 5). The latency was short; the fall in signal usually began within seconds of injection and the maximal decrease was usually seen within 1 or $2 \mathrm{~min}$. The average decrease was equivalent to a $30 \mathrm{~nm}$ fall in DA concentration; this was a clearly smaller and shorter-lasting decrease than was seen on day 1 following the first injection. Within 35 min the signal usually began to increase again, returning, on average, to slightly above the level recorded prior to the previous injection. While the second phase (the return toward baseline) of this response was evident in most of the animals that did not

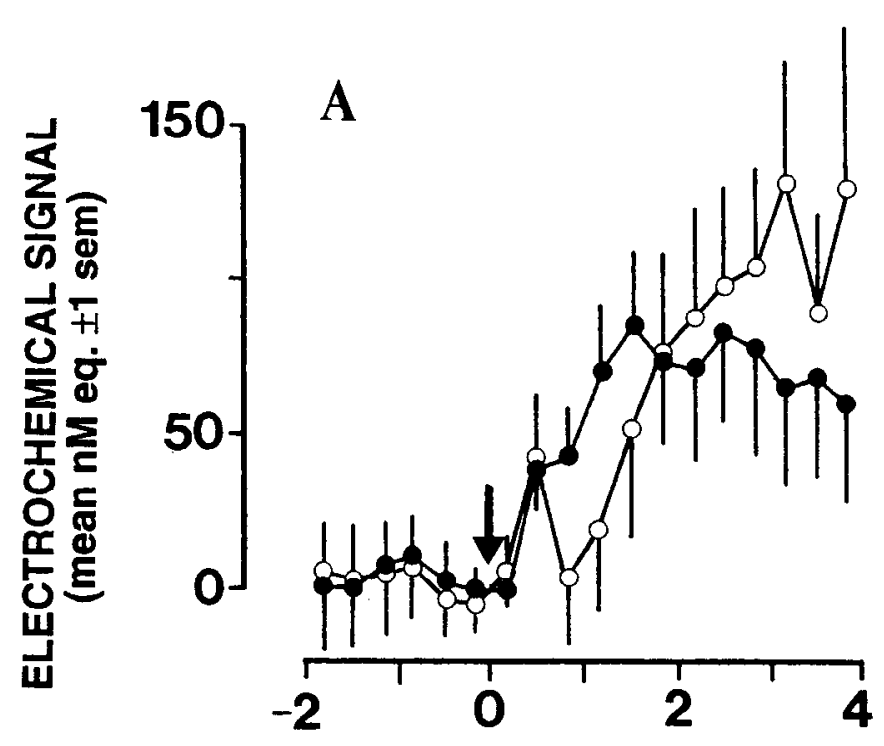

\section{TIME (min)}

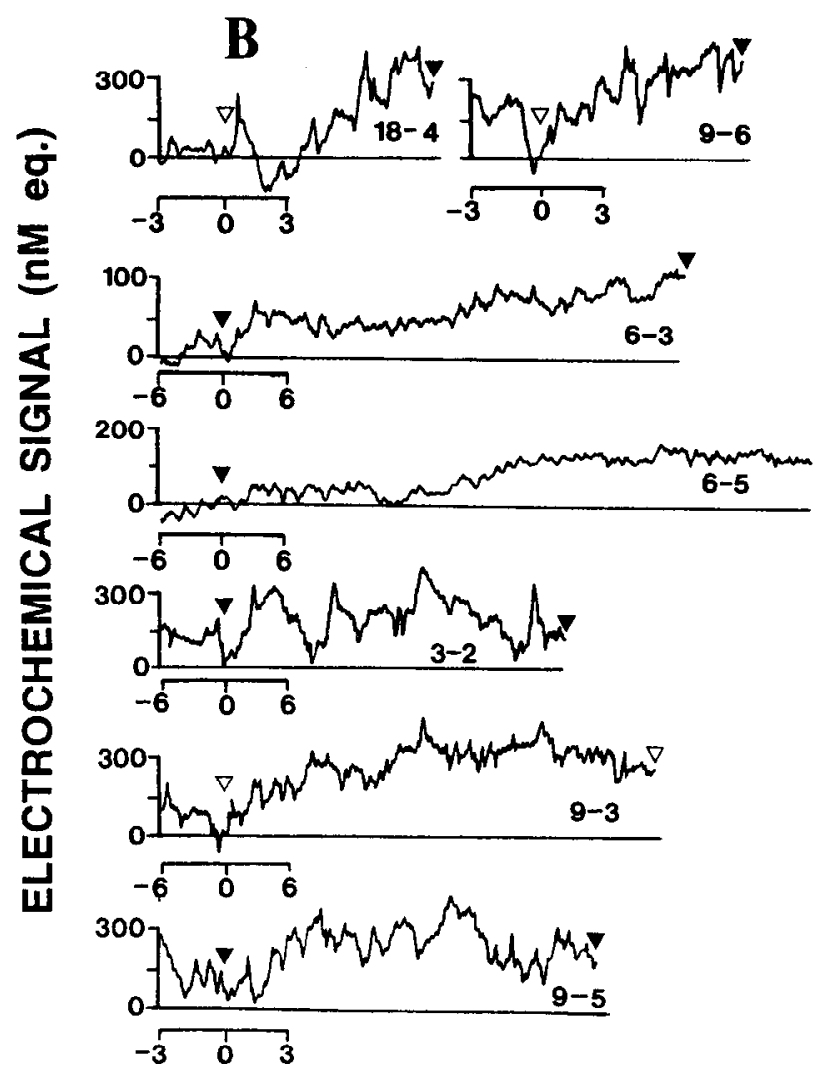

TIME (min)

Figure 4. Electrochemical response to the first cocaine injection of second and subsequent sessions. $A$, Mean $( \pm$ SEM) records from a sample of 22 self-administered (solid circles) and 8 experimenter-administered (open circles) injections. $B$. Examples of electrochemical responses to first cocaine injection recorded on days 2-6. Inverted triangles indicate time of self-administered (solid) and experimenter-administered (open) cocaine injections. 

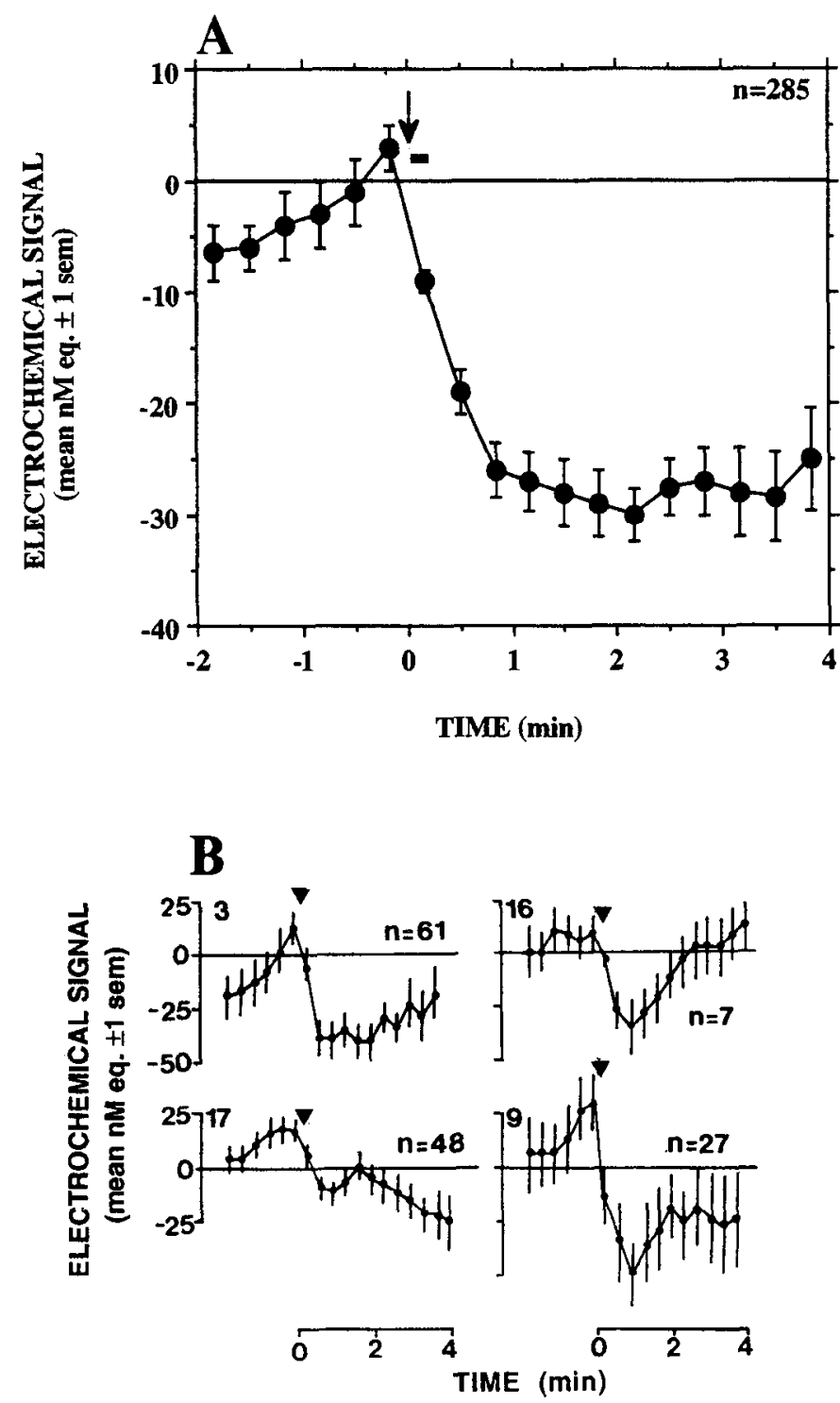

Figure 5. Mean ( \pm 1 SEM) electruchemical response to cocaine injections self-administered during second and subsequent sessions. $A$, Mean of 285 artifact-free records sampled from 12 rats. Arrow indicates time of lever press and length of bar corresponds to duration of cocaine injection. $B$, Mean records of four representative animals that are averaged in $A$. Inverted triangles indicate time of lever press. The number of records averaged in each case is indicated on the right.

respond quickly for another injection, the latency of the second phase was variable. Moreover, while profound decreases in electrochemical signal were associated with cocaine injections in some animals (e.g., animals 4, 7, and 18; Fig. 6), minimal decreases were associated with others (e.g., animals 2, 15, and 16). Data from individual animals (Figs. $5 B, 6$ ) underscore the short latency and variability in magnitude of the response. As the animals began to respond regularly, small increases in signal tended to precede lever pressing in some but not all animals (Fig. 6). A preresponse increase was evident in the overall mean (Fig. $5 A$ ) and appeared in some animals as early as the second lever press of the session.

While the immediate consequence of all but the first one to three injections on days 2-6 was to depress the electrochemical signal, the signal usually returned to a somewhat higher level between lever presses; this was true of signals recorded both on the first day and on subsequent days of testing. However, whereas the signal between each injection appeared to remain below or at the initial baseline on the first day of testing, it seemed to remain above baseline levels after the elevations caused by the light and the first injection on the second and subsequent days. Whether the signal at the end of the second and subsequent sessions was at the same level or higher or lower relative to its level immediately after presentation of the light and the first injection is difficult to determine with certainty since there was usually some degree of downward drift in the basal signal during the course of the 2-3 hr session.

Nonreinforced responses. On 18 occasions, either within or at the end of sessions, animals were allowed to lever press but the expected injection was withheld. Nonreinforced lever presses were followed by variable electrochemical responses but the mean electrochemical signal increased slowly over the $4 \mathrm{~min}$ following the response (Fig. $7 A$ ). In some animals the increase was very profound (e.g., animals 6 and 7; Fig. 7B); in other cases it was not evident in the raw records (e.g., animals 9 and 12).

End of session. Two hours after the beginning of self-administration sessions, access to the lever was blocked by a glass jar; the lever remained visible but unreachable. In several cases, one or two unrewarded lever presses were allowed before access to the lever was blocked at the end of sessions. When the lever was blocked or the injections were discontinued, there was generally an immediate increase in general locomotion and numerous attempts to reach the lever. Stereotyped movements characteristic of the self-administration phase usually ceased within 15-25 min after the last injection. Some animals made only limited attempts to reach the lever, and their stereotypy and locomotion ceased more rapidly. Some animals continued to locomotc and paw at the glass jar for a full hour after the last injection.

Mean electrochemical signal increased over the first $15 \mathrm{~min}$ of this period (Fig. $8 A, B$ ). Increases were variable, and some animals showed increases for as long as an hour after the last injection. While mean electrochemical signal stabilized after 15 min, variability increased throughout the hour. The elevations were seen on the first as well as subsequent days, with no sign of a significant progression across days.

\section{Discussion}

The present data indicate that there are phasic and tonic changes in dopamine-associated events correlated with aspects of cocaine self-administration, and that some of these correlates change with the development of a self-administration habit. The phasic fluctuations emphasize the importance of studying selfadministration with methods having moment-to-moment temporal resolution, such as voltammetry and extracellular unit recording. Unfortunately, while the temporal resolution of voltammetry is important, voltammetry-and to a greater extent single-cell recording-does not have the degree of neurochemical resolution that is ultimately desirable.

Interpretation of the present data is complicated by the fact that cocaine has opposite effects on extracellular DA and DOPAC concentrations, each of which can contribute to voltammetric signals. While the electrodes are much less sensitive to DOPAC than to DA, DOPAC concentration is perhaps 300 times higher than DA concentration in NAcc; thus, fluctuations in DOPAC concentration are a continuing problem for voltammetric studies (Dayton et al., 1981; Gonon et al., 1984). In the 

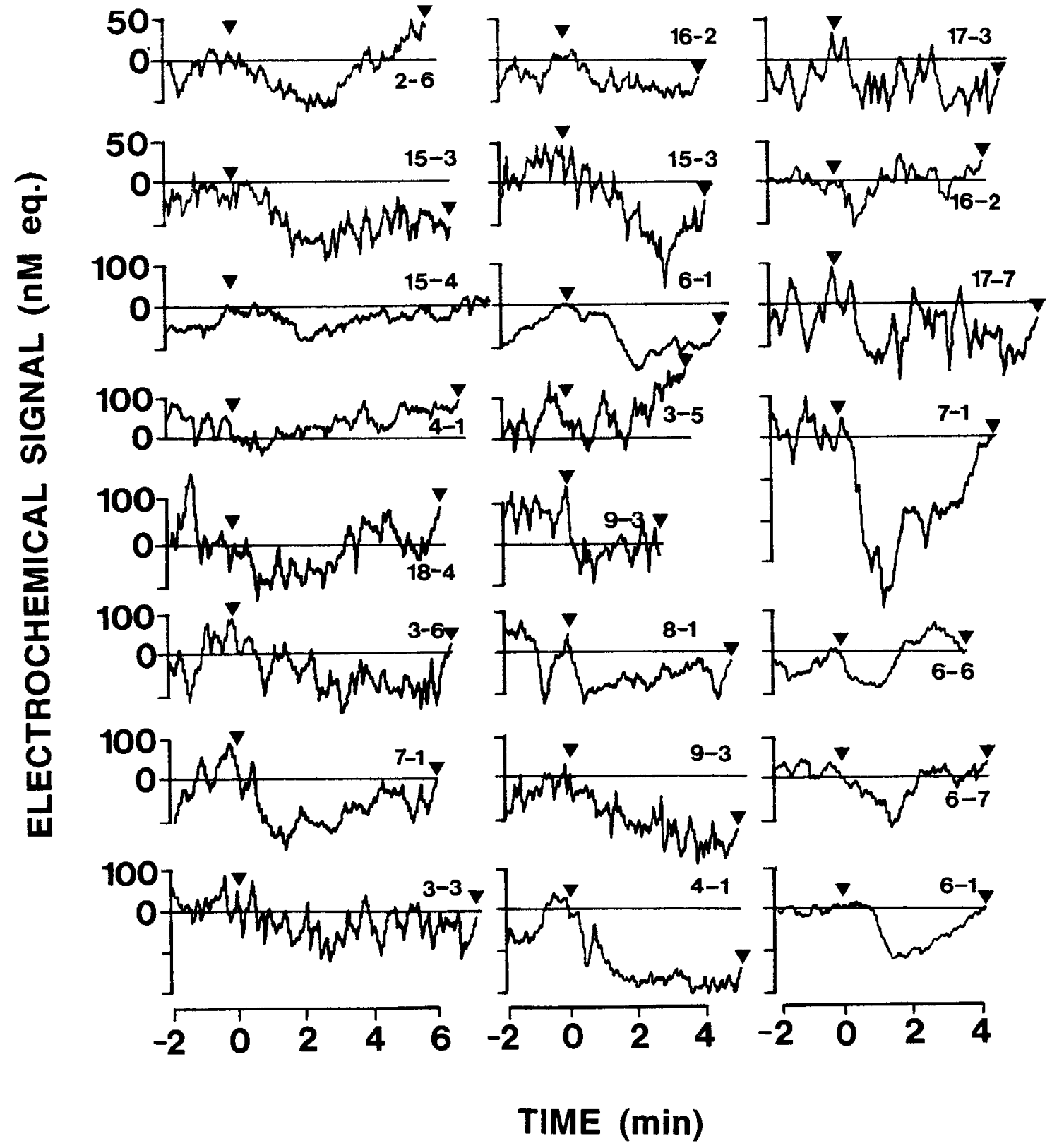

Figure 6. Representative electrochemical signals recorded during second and subsequent self-administration sessions. Inverted triangles indicate time of each lever press.

cases where there was an immediate increase in signal (e.g., the light at the start of the sessions and the initial injections on days $2-6$ ), it is reasonably certain that the cause was an increase in DA concentration. In cases where there was a decrease in signal, the source is less clear. It is difficult to attribute immediate decreases to reductions in DOPAC levels, since cocaine-induced decreases in DOPAC typically have longer latencies than cocaine-induced increases in DA (Kalivas and Duffy, 1990; Kuczenski et al., 1991).

While the present data suggest, in agreement with Pcttit and Justice $(1989,1991)$ but not with Hurd et al. (1989, 1990), that intravenous cocaine self-administration is generally accompanied by elevated levels of DA in the NAcc, they suggest that this does not occur on the first occasion that the animals receive cocaine. Moreover, the present data suggest that DA levels are elevated at the time of, and rise just before, the animal initiating a response for drug; conversely, they suggest that either a small reduction in DA levels or a large reduction in DOPAC levels is the consequence of all but the first one or two injections of the day. Neither of these findings is in agreement with recent addiction theory (e.g., Dackis and Gold, 1985; Wise and Bozarth, 1987; Koob and Bloom, 1988). Because these findings fit poorly with theories based on the known acute actions of cocaine and because they are also at odds with several reported findings in microdialysis studies, it is important to examine closely the possibility that the changes in voltammetric signal in the present experiment-particularly the decreases-might reflect something other than fluctuations of extracellular DA.

\section{Contributions to the electrochemical signals}

The conditions in which oxidation of DA is maximized are conditions in which a number of other constituents of NAcc are 

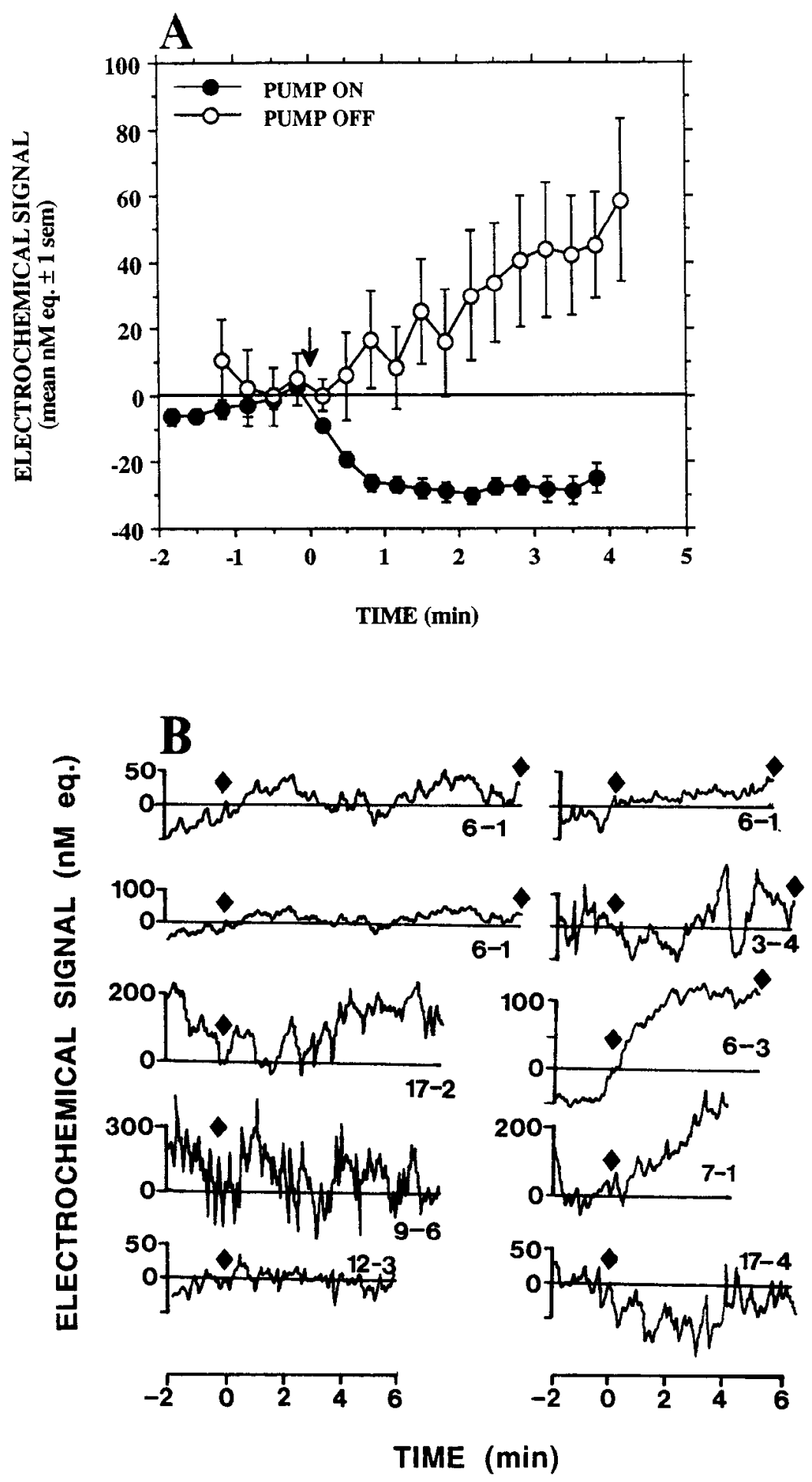

Figure 7. Changes in electrochemical signal associated with nonreinforced lever pressing. $A$, Mean ( \pm 1 SEM) records of 285 reinforced (pump on; solid circles) and 18 nonreinforced (pump off; open circles) lever presses. $B$, Individual electrochemical records of nonreinforced lever presses. Diamonds indicate time of lever presses.

TIME (min)

also oxidized. Several approaches to differentiating the contributions of various extracellular constituents of NAcc have been developed. The most important of these in the present study were the use of the perfluoro ionomer Nafion to reduce the electrode sensitivity to anions and the use of reduction as well as oxidation currents to characterize the primary electroactive species contributing to changes in the electrochemical signal. The Nafion coating on the electrodes promotes the exchange of cations such as DA and impedes the exchange of anionic species, notably AA and DOPAC (Gerhardt et al., 1984; Brazell et al., 1987; Capella et al., 1990). In the present study, only electrodes with DA-to-AA selectivity ratio of at least 1000:1 were selected for use (range $=1000-2000: 1$ ); the DA-to-DOPAC ratio of these electrodes ranged from 400:1 to $600: 1$. Still, although estimates vary considerably, it is clear that extracellular concentrations of DOPAC and AA are 2-3 orders of magnitude higher than that of DA (Schenk et al., 1982; Akimoto et al., 1990; Kalivas and Duffy, 1990; Kuczenski et al., 1991). Thus, electrode selectivity 


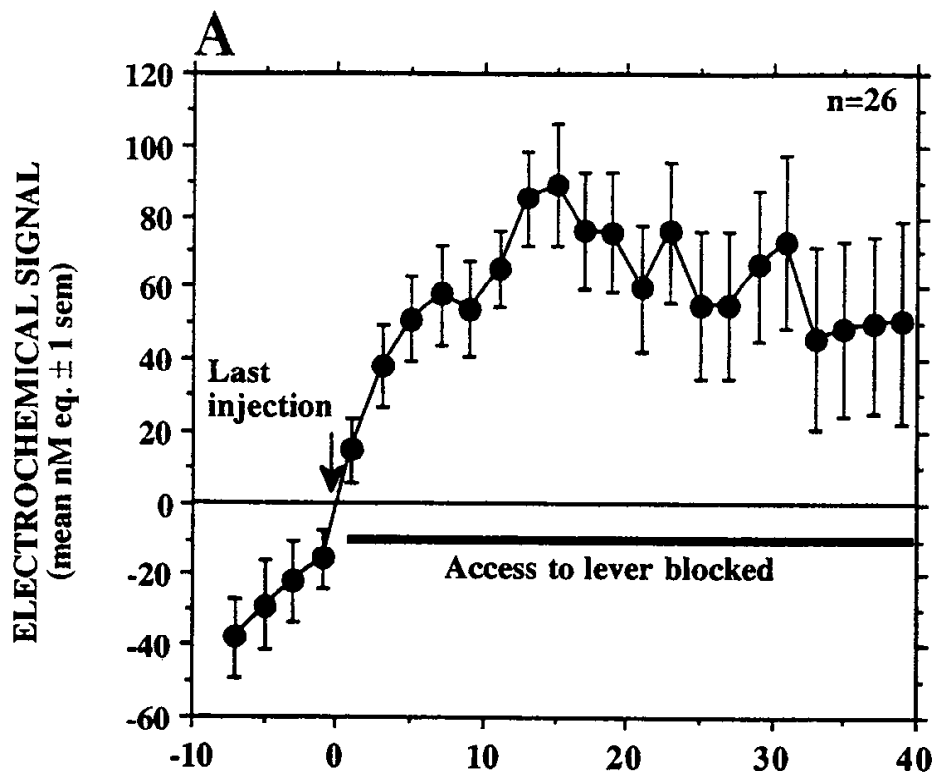

TIME (min)

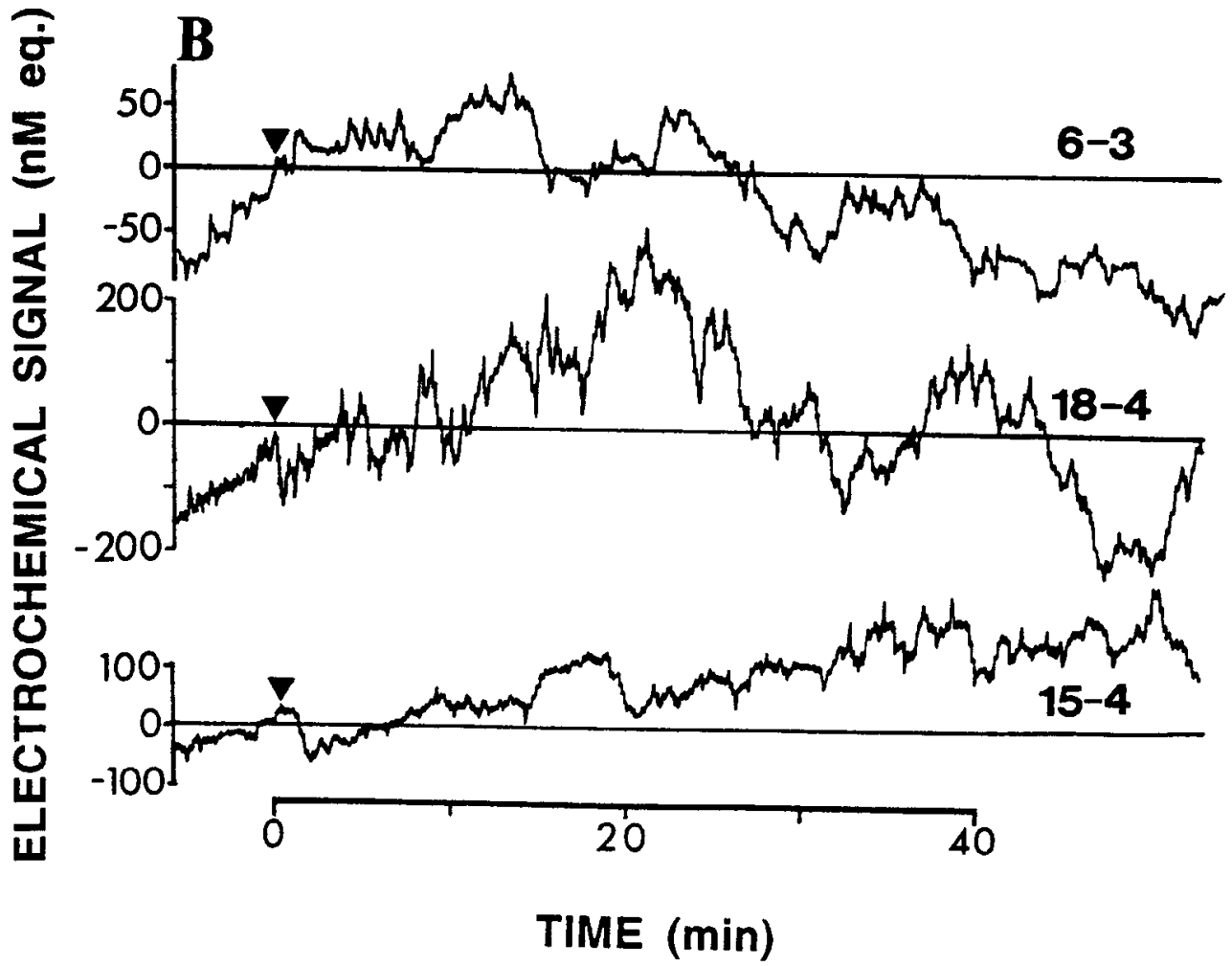

Figure 8. Changes in electrochemical signal associated with the period following the last reinforced injection of the session. $A$, Mean $( \pm 1$ SEM) of 26 records. $B$, Individual records. Inverted triangles indicate time of last injection after which access to the lever was blocked by a glass jar.

alone does not rule out fluctuations in AA or DOPAC as potential contributions to the observed fluctuations in oxidation current.

A second method for discriminating DA from other species involves comparison of oxidation and reduction currents. In the present study, changes in reduction current were consistently found to be between $65 \%$ and $100 \%$ (mean $=89 \pm 0.02 \%$ ) of the corresponding changes in oxidation current, ruling out changes in AA levels as the source of the fluctuations of interest (Gerhardt et al., 1989; Gratton et al., 1989). Fluctuations of
5-HT can also be ruled out as a significant contribution to the fluctuations reported here, since the 5 -HT reduction current falls between $10 \%$ and $20 \%$ of the oxidation current. Unfortunately, the current generated during the reduction of DOPAC is high $(90-100 \%$ of oxidation current); the reduction currents of DA and DOPAC are sufficiently similar as to make discrimination of these two species problematic using this criterion alone. Reduction current for noradrenaline is $40-50 \%$ the level of oxidation current, but the sensitivity of these electrodes to noradrenaline and the levels of noradrenaline in this region are each 
sufficiently low to rule out fluctuations in noradrenaline as an important contribution to the changes in electrochemical signal reported here.

Thus, DOPAC is the only substance known to be present in sufficient concentration in NAcc and known to oxidize at the applied potential that is likely to have contributed importantly to the correlated fluctuations in oxidation and reduction currents that were the primary data of the present study. Cocaine is known to produce slow and long-lasting decreases in extracellular DOPAC, at least in NAcc (little change or even increases seem more typical of the striatum: Hurd et al., 1990; Kuczenski et al., 1991; but see Hurd and Ungerstedt, 1989), presumably by depriving intracellular monoamine oxidase of substrate; the decreases are usually detected shortly after detection of increases in extracellular DA (Di Chiara and Imperato, 1988; Hurd and Ungerstedt, 1989; Kalivas and Duffy, 1990; Kuczenski et al., 1991). Thus, it seems reasonable to proceed on the working hypothesis that the correlated increases in oxidation and reduction currents observed in the present study are largely a reflection of the well-known ability of cocaine to block DA reuptake and elevate extracellular DA concentrations. The decreases in voltammetric signal are more problematic; they may reflect decreases in DOPAC rather than-or concurrent withdecreases in DA. The decreases in voltammetric signal must be interpreted cautiously, but it seems likely that the immediate decreases in signal reflect decreases in DA rather than DOPAC. Since this is not the expected pharmacological consequence of the drug itself, immediate decreases in voltammetric signal are likely to reflect decreases in DA concentration resulting from immediate decreases DAergic cell firing, such as are often associated with the stimulus events of food reinforcement (see, e.g., Kosobud et al., 1992; Ljungberg et al., 1992; Schultz et al., 1992).

\section{Tonic changes during self-administration}

The rapid increase in electrochemical signal seen on days 2-6 following the first cocaine injection is consistent with the microdialysis data of Pettit and Justice $(1989,1991)$ in which DA levels were rapidly (first sample) increased to $300-400 \%$ of normal; the agreement of the voltammetric data with the microdialysis data of Pettit and Justice (1989, 1991) gives credence to the assumption that fluctuations in the voltammetric signals reflect, for the most part, fluctuations in DA concentration in NAcc. Whether or not the initial increase in signal reported here was sustained throughout the session as was the increase in DA levels reported by Pettit and Justice $(1989,1991)$ is not as clear. Unlike microdialysis, which provides measures of absolute levels of DA concentration, voltammetry provides measures of changes in DA concentration relative to an undetermined baseline concentration. For this reason, voltammetric techniques are more useful for detecting rapid changes in DA levels associated with events such as a lever press than for measuring sustained changes in DA levels. Measurements of sustained druginduced effects are complicated by the slow, downward drift in signal that characterizes voltammetric recordings. Although the drift over $20-30 \mathrm{~min}$ is negligible, it can amount to a significant decrease in the basal signal by the end of a 2-3 hr self-administration session. Thus, the error in estimating the level of the signal relative to the preinjection baseline increases as the session progresses. It remains that the signal was clearly elevated above baseline during the $30-60 \mathrm{~min}$ that followed the initial cocaine injections, and in this respect, at least, our data are consistent with those of Pettit and Justice $(1989,1991)$. However, voltammetric as well as microdialysis evidence of tonic increases in DA levels by cocaine should be interpreted cautiously for other reasons. Sustained elevations of extracellular levels of DA in NAcc should result in increased activation of release- and synthesis-modulating autoreceptors, which should in turn lead to decreases in DA release (Mereu et al., 1985; Timmerman et al., 1989) and synthesis (Galloway, 1990). Presumably, compensatory decreases in DA release and synthesis would contribute to slow the extracellular accumulation of DA resulting from uptake inhibition, and over the long run perhaps also cause DA levels gradually to return at least partially toward baseline levels.

The present data and those of Pettit and Justice $(1989,1991)$ do not fit well with the data of Hurd et al., who found no increases in NAcc (1989) or caudate (1990) DA levels during cocaine self-administration in trained animals. While Hurd et al. did see elevated DA levels in untrained rats that received passive injections controlled by a "yoked" experimental partner, the data from the two Hurd et al. experiments were strikingly different in this regard. The immediate and sustained increase in DA seen in caudate dialysate of untrained animals (Hurd et al., 1990) was consistent with that seen in the present study and that seen in the NAcc dialysate of Pettit and Justice (1989, 1991). However, the increases in DA taken from NAcc dialysate (Hurd et al., 1989) were very gradual and, in this regard, inconsistent with the present data, the data of Pettit and Justice $(1989,1991)$, and the data from the caudate study of Hurd et al. (1990). Instead of an immediate increase in DA concentration, the Hurd et al. (1989) data from NAcc showed a gradual increase that reached peak levels only $1.5 \mathrm{hr}$ after the onset of cocaine injections. Since the essential difference between the two Hurd et al. studies was cannula placement, it is possible that the differences between the Hurd et al. study of NAcc and the present study and those of Pettit and Justice are also related to cannula placement. Microdialysis probes cause considerable damage because of their size, and injury-induced DA release is known to obscure functional DA release when sufficient time is not allowed for recovery after placement of a probe. In the studies of both Pettit and Justice $(1989,1991)$ and Hurd et al. (1989, 1990), removeable probes were put in place $1-2$ hr prior to initial measurements. Traditional indices of functional recovery-tetrodotoxin sensitivity (Westerink et al., 1987) and calcium dependence (Westerink et al., 1988) of basal DA levels-were not taken, and it cannot be determined whether differences in tissue damage contributed to differences in the findings of the two groups. It appears that the microdialysis probe was inserted through $5.8-6.8 \mathrm{~mm}$ of intact tissue in the case of the Hurd et al. experiments and $2 \mathrm{~mm}$ of tissuc in the Pettit and Justice experiments; in the Pettit and Justice experiments, a stylet was used to block the guide cannula, but it was not reported whether the stylet penetrated the to-be-dialyzed tissue, thus reducing the amount of damage that would be done by the probe insertion on the day of testing (Devine et al., 1993).

Several factors other than probe or electrode placement might also contribute to the differences between the Hurd et al. studies on the one hand and the Pettit and Justice and present studies on the other. One factor of potential significance is the presence or absence of environmental stimuli with conditioned motivational significance. In the present study, no elevation in DA signal was caused on the first day by the light stimulus that was used to signal the start of self-administration sessions and no 
sustained elevation was caused by the subsequent self-administered cocaine injections on that day. However, on subsequent days the light stimulus caused a large increase in signal and a further increase was caused by the first cocaine injection and seemed maintained over the course of the subsequent injections. The release of DA in response to a drug-associated stimulus is of considerable importance, and the degree of response seen in the present study was much stronger than has been seen using other paradigms (Brown and Fibiger, 1992; Fontana et al., 1991).

Presumably, the increase in DA release caused by conditioned stimuli reflects sensory-evoked impulse flow (or some presynaptically mediated impulse-independent control of release: Giorguieff et al., 1977; Clow and Jhamandas, 1989; but see Keefe et al., 1992) in the mesolimbic system. Since cocaine is a DA uptake inhibitor but not a releaser (Heikkila et al., 1975), the ability of cocaine to elevate DA levels depends on DA release triggered by other than cocaine's own influence (indeed, cocaine inhibits impulse flow and thus impulse-dependent DA release). Electrophysiological studies have demonstrated such a role for food-associated stimuli in the control of DAergic impulse flow in rats (Kosobud et al., 1992) and monkeys (Ljungberg et al., 1992) working for food. The animals of Pettit and Justice were trained to expect food reward as a consequence of lever pressing, and thus the stimuli associated with lever pressing may have served as a conditioned motivational stimulus. These considerations do not explain the elevations seen by Hurd et al. (1989, 1991) in inexperienced animals that received unsignaled injections. In this case, however, the injections themselves may have been experienced as stressful; yoked control animals receiving brain stimulation reward appear to show stronger elevations of NAcc DA than animals earning the stimulation (P. Bauco, R. Rivest, and R. A. Wise, unpublished observations). In the case of the well-known elevations of extracellular DA seen in anesthetized animals, at least some commonly used anesthetics, such as chloral hydrate, appear to activate DA cell firing (Bunney et al., 1973).

It is particularly surprising that Hurd et al. (1989) saw no elevation of DA levels during cocaine self-administration in experienced animals but did report evidence of elevations in drug-naive animals just learning to self-administer the drug. Pettit and Justice (1989, 1991) found that experienced animals had elevated DA levels in NAcc during cocaine self-administration, and in the present study there was no sign of a decrease in the elevation of DA through $6 \mathrm{~d}$ of self-administration. The findings of Hurd et al. are also difficult to reconcile with the effects of repeated high doses of systemic cocaine; most workers have reported that cocaine causes progressively greater increases in extracellular DA accumulation with repeated days of administration (Akimoto et al., 1989; Kalivas and Duffy, 1990; Pettit et al., 1990; but see Segal and Kuczenski, 1992). A factor that can affect DA levels in cocaine-experienced animals has to do with the aftereffects of cocaine exposure; there is apparent DA depletion following high-dose cocaine exposure (Parsons et al., 1991 ; M. W. Robertson et al., 1991; Imperato et al., 1992), and samples taken at different intervals or following different dosing regimens can differ bccausc of differences in the withdrawal condition (Kalivas and Duffy, 1993). However, self-administered levels of cocaine were given daily for approximately $3 \mathrm{hr}$ for $6 \mathrm{~d}$ in the present study, $9 \mathrm{~d}$ in the studies of Hurd et al. $(1989,1990)$, and an unspecified number of days that met a similar criterion of stability in the studies of Pettit and Justice $(1989,1991)$. Thus, the differences between the experienced animals of the present study, the studies of Pettit and Justice (1990, 1991), and the studies of Hurd et al. $(1989,1990)$ remain unexplained.

\section{Phasic changes associated with each response}

Perhaps more troublesome than the inconsistencies between studies with respect to the tonic elevation of DA levels are the unexpected findings that voltammetric signals were elevated and rising at the time of each lever press and that they decreased shortly after each cocaine injection. It is known that rats closely regulate their amphetamine and cocaine intake in intravenous self-administration experiments (Pickens and Thompson, 1971; Yokel and Pickens, 1973, 1974; Gerber and Wise, 1989). Animals compensate for variations in dose per injection and in work requirements to maintain a relatively constant hourly intake of drug. In the case of amphetamine, the trigger point for each response after the first few of the day is correlated with a fall in the blood level of drug; across a range of doses that produces very different peaks in blood amphetamine level, rats respond for additional $d$-amphetamine whenever their blood levels fall to approximately $0.2 \mu \mathrm{g} / \mathrm{ml}$ (Yokel and Pickens, 1973 1974). It has been widely assumed, however, that it is not blood levels of drug, but rather brain levels of DA, that are regulated (see, e.g., Wise, 1987; Pettit and Justice, 1989). The assumption has been that DA levels in NAcc rise and fall in unison with rises and falls in stimulant levels in the blood, and that animals respond for drug when DA levels fall back toward normal (Yokel and Pickens, 1973, 1974; Pettit and Justice, 1989; Stewart and Wise, 1992) or when DA is depleted below normal levels (Dackis and Gold, 1985). Along with this assumption has been the assumption that DA levels increase sharply with increasing stimulant levels in the blood; direct microdialysis evidence supports this assumption (Nicolaysen et al., 1988), although microdialysis studies are insensitive to very quick changes in either concentration. The present data suggest a brief dissociation of DA and cocaine levels, which might result if DAergic impulse flow ceases in the seconds prior to the penetration of cocaine into NAcc. It is not known how rapidly cocaine reaches its site of pharmacological action, but the voltammetric signals in the present study were depressed within a few scconds of the injections and did not start to rise until perhaps 2 min after injection.

If it were assumed that DAergic impulse flow and DA release were relatively constant during our experiments, the conclusion that DA levels fall as a result of cocaine injections would be inconsistent with the known pharmacological actions of cocaine. While cocaine can have local anesthetic effects on cholinergic neurons of NAcc at concentrations as low as $3 \mu \mathrm{M}$ (Gifford and Johnson, 1992), it does not decrease DA accumulation at several times this concentration (Nicolaysen et al., 1988). While cocaine decreases DA impulse flow (Einhorn et al., 1988), it presumably does so only as a consequence of having first elevated DA concentrations at autoreceptors and postsynaptic receptors in the negative feedback pathway. Moreover, cocaine increases NAcc DA levels when given by the experimenter, and it is capable of elevating DA levels well beyond the levels seen when animals self-administer this dose of cocaine (Pettit and Justice, 1989). DAergic impulse flow can be halted by overactivation of the DA system (Grace and Bunney, 1986), but cocaine, by elevating extracellular DA levels, should protect against such an event. Thus, it would seem that the immediate decreases observed in the present experiment are likely to represent fluctuations in the impulse flow or in presynaptic inputs that cause DA release. 
Changes in impulse flow have been reported in studies of food reward (Kosobud et al., 1992; Ljungberg eg al., 1992), and similar changes in unit activity in NAcc have been reported in drug self-administration experiments (Chang et al., 1991; Henriksen et al., 1992; Woodward et al., 1992).

It is particularly clear that cocaine craving and initiation of cocaine-reinforced lever pressing are not simple correlates of DA depletion as predicted by opponent-process models (e.g., Dackis and Gold, 1985; Koob and Bloom, 1988; Koob et al., 1989; Imperato et al., 1992); rats frequently respond for cocaine when their NAcc DA levels are unambiguously and strongly elevated (Hurd et al., 1989, 1990; Pettit and Justice, 1989, 1991; present study). While it is clear that extracellular DA levels are depleted following withdrawal from chronic cocaine treatment (Parsons et al., 1991; M. W. Robertson et al., 1991; Imperato et al., 1992), and while such depletion can apparently occur following as little as $6 \mathrm{hr}$ of self-administered intravenous cocaine (Markou and Koob, 1991), the probability of cocaine selfadministration is markedly lower during the period of DA depletion than it is following a "priming" injection of cocaine, which, at least in normal animals (Church et al., 1987; Hurd and Ungerstedt, 1989; Pettit and Justice, 1989, 1991; but see Hurd et al., 1989, 1990) elevated DA levels. Probability of responding is tightly constrained once the animal has initiated responding at the beginning of a session (Gerber and Wise, 1989), and the data from the present study and those of Pettit and Justice $(1989,1991)$ indicate that NAcc DA levels are substantially elevated throughout the period of self-administration (except for the first day of testing). If the initiation of a drugreinforced operant like lever pressing can be taken as a reliable indication of motivation (see, e.g., Teitelbaum, 1966), the motivation to take drug is lower at the begining of the session, when DA levels are depleted, than during the session, when DA levels are usually elevated.

The present study further suggests [unless the decreases in signal following each injection represent large (micromolar) and immediate decreases in DOPAC, which seems improbable primarily because DOPAC concentrations are not that labile] that cocaine reinforcement is not a simple correlate of elevation of extracellular DA levels, as predicted by simple reward models. This finding, more than any other, is in apparent contradiction with the now widely held view that DA release plays a critical role in positive rewards in general (Wise et al., 1978; Wise, 1982, 1989; Wise and Rompré, 1989) and psychomotor stimulant reward in particular (Fibiger, 1978; Wise, 1987, 1989). While voltammetric signals increased within a few minutes after each injection, it is the period just following the operant response that holds the greatest importance for reinforcement (Perin, 1943; Harker, 1956; Black et al., 1985). There was rarely any sign of increased DA release in the first 2 min after each lever press. Rather, the immediate consequence of lever pressing appeared to be a decrease in the DA-associated signal.

It has been widely assumed that the apparent regulation of amphetamine (Yokel and Pickens, 1973, 1974; Dougherty and Pickens, 1974) and cocaine (Gerber and Wise, 1989) intake was a reflection of the correlated "regulation" of some endogenous neurochemical event such as the synaptic concentration of DA in NAcc (Wise, 1987; Pettit and Justice, 1989). While the details of this assumption have not been formally discussed, the facts that animals are known not to find high doses of amphetamine aversive (Iglauer et al., 1976; Yokel, 1987) or motorically debilitating (Wise et al., 1977), suggested that responding for psy- chomotor stimulants is spaced because the drug loses its effectiveness when blood levels are elevated significantly beyond some critical level (Yokel and Pickens, 1973, 1974). One possibility would be, for example, that there is a limit to the ability of amphetamine or cocaine to elevate DA levels; another logical possibility [ruled out by the demonstration by Pettit and Justice (1989) that more frequent injections cause more elevated DA levels] would be that the relevant DA receptors become saturated during unlimited self-administration conditions. In either case, the result would be that the animal pauses between responses until blood levels of drug and synaptic levels of transmitter fall to below some limiting ceiling. The present data appear to rule out such possibilities, suggesting, instead, that fluctuations in blood drug levels are inversely related to NAcc DA levels. This suggestion is inconsistent with what is currently known about the direct pharmacological effects of amphetamine and cocaine but gains credibility when electrophysiological effects of cocaine and of other rewarding events are considered.

First, cocaine is a DA uptake inhibitor but not a DA releaser (Heikkila et al., 1975; Van der Zee et al., 1980; Nomikos et al., 1990; Pani et al., 1990); thus, the ability of cocaine to elevate extracellular DA levels is entirely dependent on extracellular DA that is released either by impulse flow in the DAergic axons or by impulse-independent presynaptic influences (Giorguieff et al., 1977; Clow and Jhamandas, 1989). Since cocaine is an inhibitor of DAergic cell firing (Einhorn et al., 1988), it must be considered an inhibitor of impulse-dependent DA release; the inhibition of DAergic impulse flow apparently results from feedback effects of cocaine that include elevation of extracellular DA at somatodendritic autoreceptors (Robertson et al., 1991). One possible mechanism for a decrease in extracellular DA release in NAcc would be a decrease in impulse flow caused by the immediate effects of cocaine at the DAergic cell body. It remains, however, that the inhibitory effect of cocaine on impulse flow is only partly mediated by presynaptic mechanisms. Complete inhibition of impulse flow by cocaine would also have to involve postsynaptic mechanisms that feed back to DAergic cell bodies (Einhorn et al., 1988) and would therefore require that DA levels increase at both the cell body and the terminal. While the present data suggest that DA levels at the terminal were increasing during the few minutes leading up to the time of injection, there was no evidence that levels continued to increase after the injection before they started to decrease.

\section{Evidence of conditioned $D A$ release}

The elevation in signal seen following the light stimulus but preceding any drug injections on the second and subsequent days seems likely to reflect a conditioned DA release. Several investigators have reported suggestive cvidence that rewardassociated stimuli can themselves come to induce elevated extracellular DA. Blackburn et al. (1989) have found increases in DOPAC:DA ratios, an index of DA turnover, in the NAcc of rats exposed to environmental stimuli that signaled an incipient meal. Pfaus et al. (1990) have found microdialysis evidence of increased DA release in the NAcc of rats exposed to an environment where other rats had recently copulated; further increases were seen when a receptive female was placed in an adjacent chamber that allowed visual, olfactory, and tactile exploration but did not allow copulation. Further increases were seen with the two animals were allowed to copulate. Similarly, Mitchell and Gratton $(1991,1992)$ found in vivo electrochemical evidence of increased DA release in NAcc of rats presented with 
bedding from cages of estrus females. Increases in voltammetric signals have been recorded in both the feeding (Mitchell and Gratton, 1992) and copulation paradigms (Phillips et al., 1991). Kalivas and Duffy (1990) found microdialysis evidence of increased NAcc DA when rats with a history of cocaine injections were given saline injections and placed in the cocaine-associated testing environment. While Brown and Fibiger (1992) were unable to detect microdialysis evidence of increases in NAcc DA when rats were placed in an environment where they had received previous cocaine injections-despite the fact that this environment elicited conditioned locomotion-Fontana et al. (1991) found enhanced locomotion and elevated NAcc DA in animals given acute cocaine injections in an environment where they had received them previously. In the present experiment, the light that was paired with each cocaine injection during the first day of self-administration training caused a profound increase in voltammetric signal when presented at the beginning of the self-administration period on day 2 (and subsequent days); the light had no such effect when presented at the beginning of the self-administration period on day 1 , prior to the pairing of light with cocaine injections. While the effects of the light were not assessed after uncorrelated presentations of the light and cocaine, it seems likely that it was the association of the light stimulus with cocaine on the first day of testing that made the light effective in increasing the voltammetric signal on days 26. Such conditioned DA release could play a very important role in cocaine-induced elevation of extracellular DA concentrations, since cocaine can prolong the life of synaptic DA by suppressing DA reuptake, but cannot elevate extracellular DA in the absence of some other source of DA release (Heikkila et al., 1975; McMillan, 1983).

\section{Relation of voltammetric changes to initiation of movernent}

The phasic changes in voltammetric signal correlated, to some extent, with the initiation of lever presses or attempts to gain access to the lever. For example, the animals were relatively inactive for 1 or 2 min after each rewarded lever press during the period when the voltammetric signal quickly fell. The animals were active and their attention was increasingly focused (on the lever) in the period before lever presses, when the voltammetric signal was rising. When expected cocaine injections were withheld, there were phasic increases in signal that correlated with further responses or with attempts to gain access to the response lever. However, the correlations were with the rate of change of the voltammetric signal, and not with its absolute level. Profound stereotypy was seen when the signals were low on the first day and midway between lever presses. Once again, the explanation might be reflected in recording studies; phasic changes in DA-associated unit activity also correlate with the focusing of attention that precedes the initiation of lever pressing (Henriksen et al., 1992; Kosobud et al., 1992; Woodward et al., 1992). These observations are consistent with the notion that the central correlates of two classes of movement can be distinguished and might be roughly designated "volitional" and "automatic," as was once widely discussed in relation to "theta" activity in the hippocampal electroencephalogram.

\section{Suggested working hypotheses}

Further work is clearly needed with this challenging preparation, since, at the moment, it offers the only method for conducting neurochemical studies with sufficient temporal resolution to be correlated with the most interesting data from electrophysiological studies (Chang et al., 1991; Henriksen et al., 1992; Woodward et al., 1992) of drug self-administration. A major challenge for future voltammetric studies is to provide more positive discrimination between changes in DA and changes in DOPAC levels. Despite this limitation of the present study, however, the present data suggest several hypotheses that are only beginning to be suggested in the literature but that are consistent with it.

First, the lack of a clear increase in DA-related signal in response to the first cocaine injection on the first day, coupled with the presence of such increases on all subsequent days, underscores the fact (Heikkila et al., 1975; McMillan, 1983) that the ability of cocaine to elevate DA levels depends on some other source of DA release. Since cocaine itself inhibits DA relcasc, its ability to block rcuptake would have little effect if there were not some other releasing stimulus present in the situation. It may have been widely assumed that the DAergic cells are tonically active, but it is clear from electrophysiological studies that this is not always the case. The firing of DAergic (Kosobud et al., 1992; Ljungberg et al., 1992) and dopaminoceptive (Chang et al., 1991; Henriksen et al., 1992; Woodward et al., 1992) neurons during operant behaviors-including cocaine-reinforced operant behavior-fluctuates significantly both before and after operant responding, and DAergic neurons are most likely to be excited before and to be inhibited after a welltrained response.

Second, since the cocaine-associated light stimulus caused an immediate and dramatic increase in voltammetric signal, it appears that DA release is triggered by synaptic input from rewardassociated conditioned stimuli. Conditioned release or stressinduced release may be necessary to overcome cocainc-induced suppression of DAergic firing (Einhorn et al., 1988) and produce sufficient DA release to provide a substrate for cocaine-dependent DA accumulation.

Finally, the present data raise the possibility - argued by others in the context of more natural reinforcers (Ljungberg et al., 1992; Phillips et al., 1992) - that the DAergic system is more activated in anticipation of reward than it is in the actual receipt of reward. This possibility is consistent with our findings of similar anticipatory increases and postreinforcement decreases in voltammetric signals in rats lever pressing for intravenous heroin (Kiyatkin et al., 1993) or for food pellets (Kiyatkin and Gratton, in preparation). In these cases, it is very difficult to attribute the decreases in voltammetric signal to decreases of anything but DA. Since the up-down-up pattern of voltammetric signals in animals working for food reward must necessarily be synaptically driven, it seems likely that increases in DAergic impulse flow are common to anticipation not only of food reward (Ljungberg et al., 1992; Schultz et al., 1992) but also of psychomotor stimulant (Chang et al., 1991; Kosobud et al., 1992; Woodward et al., 1992) and opiate reward (Henriksen et al., 1992) as well. Similarly, it seems likely that decreases in DAergic impulse flow are associated with the receipt of each of these very different rewards.

\section{References}

Acquas E, Di Chiara G (1992) Depression of mesolimbic DA transmission and sensitization to morphine during opiate abstinence. $J$ Neurochem 58:1620-1625.

Akimoto K, Hamamura T, Otsuki S (1989) Subchronic cocaine treatment enhances cocaine-induced DA efflux, studied by in vivo intracerebral dialysis. Brain Res 490:399-344.

Akimoto K, Hamamura T, Kazahaya Y, Akiyama K, Otsuki S (1990) 
Enhanced extracellular DA level may be the fundamental neuropharmacological basis of cross-behavioral sensitization between methamphetamine and cocaine - an in vivo dialysis study in freely moving rats. Brain Res 507:344-346.

Baxter BL, Gluckman MI, Stein L, Scerni RA (1974) Self-injection of apomorphine in the rat: positive reinforcement by a $D A$ receptor stimulant. Pharmacol Biochem Bchav 2:387-391.

Black J, Belluzzi J, Stein L (1985) Reinforcement delay of one second severely impairs acquisition of brain self-stimulation. Brain Res 359: 113-119.

Blackburn JR, Phillips AG, Jakubovic A, Fibiger HC (1989) DA and preparatory behavior: II. A neurochemical analysis. Behav Neurosci 103:15-23.

Boja JW, Markham L, Patel A, Uhl G, Kuhar MJ (1992) Expression of a single DA transporter cDNA can confer two cocaine binding sites. Neuroreport 3:247-248

Bozarth MA, Wise RA (1985) Toxicity associated with long-term intravenous heroin and cocaine self-administration in the rat. JAMA 254:81-83.

Brazell MP, Feng J, Kasser RJ, Renner KJ, Moghaddam B, Adams RN (1987) An improved method for Nafion coating carbon fiber electrodes for in vivo electrochemistry. J Neurosci Methods 22:167-172.

Brown EE, Fibiger HC (1992) Cocaine-induced conditioned locomotion: absence of associated increases in DA release. Neuroscience 48:621-629.

Bunney BS, Walter JR, Roth RH, Aghajanian GK (1973) DAergic neurons: effect of antipsychotic drugs and amphetamine on single cell activity. J Pharmacol Exp Ther 185:560-571.

Campbell BA, Teghtsoonian R, Williams RA (1961) Activity, weight loss, and survival time of food-deprived rats as a function of age. $J$ Comp Physiol Psychol 54:216-219.

Capella P, Ghasemzadeh B, Mitchell K, Adams RN (1990) Nafioncoated carbon fiber electrodes for neurochemical studies in brain tissue. Electroanalysis 2:175-182.

Carboni E, Impcrato A, Pcrczzani L, Di Chiara G (1989) Amphetamine, cocaine, phencyclidine and nomifensine increase extracellular DA concentrations preferentially in the NAcc of freely moving rats. Neuroscience 28:653-661.

Chang JY, Sawyer SF, Lee R-S, Woodward DJ (1991) Correlation between NAcc neuronal activity and cocaine self-administration behavior in rats. Soc Neurosci Abstr 17:679.

Church WH, Justice JB Jr, Byrd LD (1987) Extracellular DA in rat striatum following uptake inhibition by cocaine, nomifensine and benztropine. Eur J Pharmacol 139:345-348.

Clow DW, Jhamandas K (1989) Characterization of L-glutamate action on the release of endogenous DA from the rat caudate-putamen. J Pharmacol Exp Ther 248:722-728.

Dackis CA, Gold MS (1985) New concepts in cocaine addiction: the DA depletion hypothesis. Neurosei Biobchav Rev 9:469-477.

Dayton MA, Ewing AG, Wightman RM (1981) Evaluation of amphetamine-induced in vivo electrochemical response. Eur J Pharmacol 75:141-144.

de Wit H, Wise RA (1977) Blockade of cocaine reinforcement in rats with the DA receptor blocker pimozide but not with the noradrenergic blockers phentolamine or phenoxybenzamine. Can J Psychol 31:195203.

Deneau G, Yanagita T, Seevers MH (1969) Self-administration of psychoactive substances by the monkey: a measure of psychological dependence. Psychopharmacologia 16:30-48.

Devine DP, Leone P, Wise RA (1993) Surgical preparation of striatal tissue facilitates early sampling in microdialysis and reveals an index of neuronal damage. $J$ Neurochem, in press.

Di Chiara G, Imperato A (1988) Drugs of abusc preferentially stimulate DA release in the mesolimbic system of freely moving rats. Proc Natl Acad Sci USA 85:5274-5278

Dougherty JD, Pickens R (1974) Effects of phenobarbital and SKR 525A on cocaine self-administration in rats. Drug Addict 3:135-143.

Einhorn LC, Johansen PA, White FJ (1988) Electrophysiological effects of cocaine in the mesoaccumbens DA system: studies in the ventral tegmental area. J Neurosci 8:100-112.

Ettenberg A, Pettit HO, Bloom FE, Koob GF (1982) Heroin and cocaine intravenous self-administration in rats: mediation by separate neural systems. Psychopharmacology (Berlin) 78:204-209.

Fibiger HC (1978) Drugs and reinforcement mechanisms: a critical review of the catecholamine theory. Annu Rev Pharmacol Toxicol $18: 37-56$.
Fisher JF, Cho AK (1979) Chemical release of DA from striatal homogenates: evidence for an exchange diffusion model. J Pharmacol Exp Ther 208:203-209.

Fontana DJ, Post RM, Pert A (1991) Conditioned increases in mesolimbic DA overflow by stimuli associated with cocaine. Soc Neurosci Abstr 17:683.

Galloway MP (1990) Regulation of dopamine and serotonin synthesis by acute administration of cocaine. Synapse 6:63-72.

Gerber GJ, Wise RA (1989) Pharmacological regulation of intravenous cocaine and heroin self-administration in rats: a variable dose paradigm. Pharmacol Biochem Behav 32:527-531.

Gerhardt G, Oke AF, Nagy G, Moghaddam B, Adams RN (1984) Nafion-coated electrodes with high selectivity for CNS electrochemistry. Brain Res 290:390-395.

Gerhardt GA, Friedman M, Brodie MS, Vickroy TW, Gratton A, Hoffer BJ, Rose GM (1989) The effects of cholecystokinin (CCK-8) on DAcontaining nerve terminals in the caudate nucleus and NAcc of the anesthetized rat: an in vivo electrochemical study. Brain Res 499:157163.

Gifford AN, Johnson KM (1992) Comparison of the role of local anesthetic properties with DA uptake blockade in the inhibition of striatal and NAcc $\left[{ }^{3} \mathrm{H}\right]$ acetylcholine release by cocaine. J Pharmacol Exp Ther 263:757-761.

Giorguieff MF, Kemel ML, Glowinski J (1977) Presynaptic effect of L-glutamic acid on the release of DA in rat striatal slices. Neurosci Lett 6:73-77.

Goeders NE, Smith JE (1983) Cortical DAergic involvement in cocaine reinforcement. Science 221:773-775.

Gonon FG, Navarre F, Buda MJ (1984) In vivo monitoring of DA release in the rat brain with differential normal pulse voltammetry. Anal Chem 56:573-575.

Grace AA, Bunney BS (1986) Induction of depolarization block in midbrain DA neurons by repeated administration of haloperidol: analysis using in vivo intracellular recording. J Pharmacol Exp Ther 238:1092-1100.

Gratton A, Hoffer BJ, Gerhardt GA (1989) In vivo electrochemical determination of monoamine release in the medial prefrontal cortex of the rat. Neuroscience 29:57-64.

Guerin GF, Goeders NE, Dworkin SI, Smith JE (1984) Intracranial self-administration of DA into the NAcc. Soc Neurosci Abstr 10: 1072.

Harker GS (1956) Delay of reward and performance of an instrumental response. J Exp Psychol 51:303-310.

Heikkila RE, Orlansky H, Cohen G (1975) Studies on the distinction between uptake inhibition and release of $\left({ }^{3} \mathrm{H}\right) \mathrm{DA}$ in rat brain tissue slices. Biochem Pharmacol 24:847-852.

Henriksen SJ, Callaway CW, Negus SS, Koob GF, Miller DE, Berg GI, Friedman LR, Engberg CC (1992) Properties of neurons recorded in the rodent NAcc, in vivo: relationship to behavioral state and heroin self-administration. Soc Neurosci Abstr 18:373.

Henry DJ, Greene MA, White FJ (1989) Electrophysiological effects of cocaine in the mesoaccumbens DA system: repeated administration. J Pharmacol Exp Ther 251:833-839.

Hoebel BG, Monaco AP, Hernandez L, Aulisi EF, Stanley BG, Lenard L (1983) Self-injection of amphetamine directly into the brain. Psychopharmacology (Berlin) 81:158-163.

Hurd J, Ungerstedt U (1989) Cocaine: an in vivo microdialysis evaluation of its acute action on DA transmission in rat striatum. Synapse 3:48-54.

Hurd JL, Weiss F, Koob GF, Anden N-E, Ungerstedt U (1989) Cocaine reinforcement and extracellular DA overflow in rat NAcc: an in vivo microdialysis study. Brain Res 498:199-203.

Hurd YL, Weiss F, Koob GF, Ungerstedt U (1990) The influence of cocaine self-administration on in vivo DA and acetylcholine neurotransmission in rat caudate-putamen. Ncurosci Lett 109:227-233.

Iglauer C, Llewellyn ME, Woods JH (1976) Concurrent schedules of cocaine injection in rhesus monkeys: dose variations under independent and non-independent variable-interval procedures. Pharmacol Rev 27:367-383.

Imperato A, Mele A, Scrocco MG, Puglisi-Allegra S (1992) Chronic cocaine alters limbic extracellular DA. Neurochemical basis for addiction. Eur J Pharmacol 212:299-300.

Johanson CE, Balster RL, Bonese K (1976) Self-administration of psychomotor stimulant drugs: the effects of unlimited access. Pharmacol Biochem Behav 4:45-51 
Kalivas PW, Duffy P (1990) Effect of acute and daily cocaine treatment on extracellular DA in the NAcc. Synapse 5:48-58.

Kalivas PW, Duffy P (1993) Time course of extracellular DA and behavioral sensitization to cocaine. II. DA perikarya. J Neurosci 13 : 276-284.

Keefe KA, Zigmond MJ, Abercrombie ED (1992) Extracellular DA in striatum: influence of nerve impulse activity in medial forebrain bundle and local glutamatergic input. Neuroscience 47:325-332.

Kiyatkin EA, Wise RA, Gratton A (1993) Drug- and behavior-associated changes in dopanine-related electrochemical signals duirng intravenous heroin self-administration in rats. Synapse 14:60-72.

Koob GF, Bloom FE (1988) Cellular and molecular mechanisms of drug dependence. Science 242:715-723.

Koob GF, Stinus L, Le Moal M, Bloom FE (1989) Opponent process theory of motivation: neurobiological evidence from studies of opiate dependence. Neurosci Biobehav Rev 13:135-140.

Kosobud AE, Harris GC, Chapin JK (1992) Actions of drugs of abuse on reward-related activity in neurons of the ventral tegmental area and prefrontal cortex in the rat. Soc Neurosci Abstr 18:900.

Kuczenski R, Segal DS, Aizenstein ML (1991) Amphetamine, cocaine, and fencamfamine: relationships between locomotor and stereotypy response profiles and caudate and accumbens DA dynamics. $J$ Neurosci 11:2703-2712.

Ljungberg T, Apicella P, Schultz W (1992) Responses of monkey DA neurons during learning of behavioral reactions. J Neurophysiol 67 : $145-163$.

Loh EA, Roberts DCS (1990) Break-points on a progressive ratio schedule reinforced by intravenous cocaine increase following depletion of forebrain serotonin. Psychopharmacology (Berlin) 101:262266.

Lyness WH, Moore KE (1983) Increased self-administration of $d$-amphetamine by rats pretreated with metergoline. Pharmacol Biochem Behav 18:721-724.

Lyness WH, Friedle NM, Moore KE (1979) Destruction of DAergic nerve terminals in NAcc: effect on $d$-amphetamine self-administration. Pharmacol Biochem Behav 11:553-556.

Lyness WH, Friedle NM, Moore KE (1981) Increased self-administration of $d$-amphetamine after destruction of 5-hydroxytryptaminergic nerves. Pharmacol Biochem Behav 12:937-941.

Markou A, Koob GF (1991) Postcocaine anhedonia: an animal model of cocaine withdrawal. Neuropsychopharmacology 4:17-26.

Martin-Iverson MT, Szostak C, Fibiger HC (1986) 6-HydroxyDA lesions of the medial prefrontal cortex fail to influence intravenous self-administration of cocaine. Psychopharmacology (Berlin) 88:310 314.

McMillen BA (1983) CNS stimulants: two distinct mechanisms of action for amphetamine-like drugs. Trends Pharmacol Sci 4:429-432.

Mereu G, Westfall TC, Wang RY (1985) Modulation of terminal excitability of mesolimbic dopaminergic neurons by $D$-amphetamine and haloperidol. Brain Res 359:88-96.

Miller HH, Shore PA, Clarke DE (1980) In vivo monoamine oxidase inhibition by $d$-amphetamine. Biochem Pharmacol 29:1347-1354.

Mitchell JB, Gratton A (1991) Opioid modulation and sensitization of dopamine release elicited by sexually relevant stimuli: a high-speed chronoamperometric study in freely behaving rats. Brain Res 551 : 20-27.

Mitchell JB, Gratton A (1992) Partial dopamine depletion of the prefrontal cortex leads to enhanced mesolimbic dopamine release elicited by repeated exposure to naturally reinforcing stimuli. J Neurosci 12 3609-3618.

Nicolaysen LC, Pan H-T, Justice JB Jr (1988) Extracellular cocaine and DA concentrations are linearly related in rat striatum. Brain Res 456:317-323.

Nomikos GG, Damsma G, Wenkstern BA, Fibiger HC (1990) In vivo characterization of locally applied DA uptake inhibitors by striatal microdialysis. Synapse 6:106-112.

Pani L, Kuzmin A, Diana M, De-Montis G, Gessa GL (1990) Calcium receptor antagonists modify cocaine effects in the central nervous system differently. Eur J Pharmacol 190:217-221.

Parsons LH, Smith AD, Justice JB (1991) Basal extracellular DA is decreased in the rat NAcc during abstinence from chronic cocaine. Synapse 9:60-65.

Perin CT (1943) A quantitative investigation of the delay of reinforcement gradient. J Exp Psychol 32:37-51.

Pettit HO, Justice JB (1989) DA in the NAcc during cocaine self- administration as studied by in vivo microdialysis. Pharmacol Biochem Behav 34:899-904.

Pettit HO, Justice JB Jr (1991) Effect of dose on cocaine self-administration behavior and DA levels in the NAcc. Brain Res 539:94-102

Pettit HO, Pan HT, Parsons LH, Justice JB Jr (1990) Extracellular concentrations of cocaine and DA are enhanced during chronic cocaine administration. J Neurochem 55:798-804.

Pfaus JG, Damsma G, Nomikos GG, Wenkstern DG, Blaha CD, Phillips AG, Fibiger HC (1990) Sexual behavior enhances central DA transmission in the male rat. Brain Res 530:345-348.

Phillips AG, Mora F, Rolls ET (1981) Intracerebral self-administration of amphetamine by rhesus monkeys. Neurosci Lett 24:81-86.

Phillips AG, Broekkamp CLE, Fibiger HC (1983) Strategies for studying the neurochemical substrates of drug reinforcement in rodents. Prog Neuropsychopharmacol Biol Psychiatry 7:585-590.

Phillips AG, Pfaus JG, Blaha CD (1991) DA and motivated behavior: insights provided by in vivo analyses. In: The mesolimbic DA system: from motivation to action (Willner $\mathrm{P}$, Scheel-Krüger $\mathrm{J}$, eds), pp 199 224. New York: Wiley.

Phillips AG, Blaha CD, Pfaus JG, Blackburn JR (1992) Neurobiological correlates of positive emotional states: DA, anticipation and reward. In: International review of studies on emotion (Strongman KT, ed), pp 32-50. New York: Wiley.

Pickens R, Thompson T (1971) Characteristics of stimulant reinforcement. In: Stimulus properties of drugs (Thompson T, Pickens R, eds) pp 177-192. New York: Appleton-Century-Crofts.

Pothos E, Rada P, Mark GP, Hoebel BG (1991) Chronic morphine increases synaptic DA in the NAcc and naloxone decreases it unless withdrawal is blocked with clonidine. Soc Neurosci Abstr 17:822.

Risner ME, Jones BE (1976) Role of noradrenergic and DAergic processes in amphetamine self-administration. Pharmacol Biochem Behav $5: 477-482$

Ritz MC, Kuhar MJ (1989) Relationship between self-administration and amphetamine and monoamine receptors in brain: comparison with cocaine. J Pharmacol Exp Ther 248:1010-1017.

Ritz MC, Lamb RJ, Goldberg SR, Kuhar MJ (1987) Cocaine receptors on DA transporters are related to self-administration of cocaine. Science 237:1219-1223.

Roberts DCS, Corcoran ME, Fibiger HC (1977) On the role of ascendng catecholaminergic systems in intravenous self-administration of cocaine. Pharmacol Biochem Behav 6:615-620.

Roberts DCS, Koob GF, Klonoff P, Fibiger HC (1980) Extinction and recovery of cocaine self-administration following 6-OHDA lesions of the NAcc. Pharmacol Biochem Behav 12:781-787.

Robertson GS, Damsma G, Fibiger HC (1991) Characterization of DA release in the substantia nigra by in vivo microdialysis in freely moving rats. $J$ Neurosci 11:2209-2216.

Robertson MW, Leslie CA, Bennett JP Jr (1991) Apparent synaptic DA deficiency induced by withdrawal from chronic cocaine treatment. Brain Res 538:337-339.

Rosetti ZL, Melis F, Carboni S, Gessa GL (1991) Marked inhibition of DA release: a common neurobiological substrate for abstinence from drugs of abuse. Soc Neurosci Abstr 17:1599.

Schenk JO, Miller E, Gaddis E, Adams RN (1982) Homeostatic control of ascorbate concentration in CNS extracellular Huid. Brain Res 253:353-356.

Schultz W, Apicella P, Scarnati E, Ljungberg T (1992) Neuronal activity in monkey ventral striatum related to the expectation of reward. J Neurosci 12:4595-4610.

Segal DS, Kuczenski R (1992) Repeated cocaine administration induces behavioral sensitization and corresponding decreased extracellular DA responses in caudate and accumbens. Brain Res 577:351355.

Stewart J, Wise RA (1992) Reinstatement of heroin self-administration habits: morphine prompts and naltrexone discourages renewed responding after extinction. Psychopharmacology (Berlin) 108:779784

Strecker RE, Jacobs BL (1985) Substantia nigra DAergic unit activity in behaving cats: effect of arousal on spontaneous discharge and sensory evoked activity. Brain Res 361:339-350.

Teitelbaum P (1966) The use of operant methods in the assessment and control of motivational states. In: Operant behaviour: areas of research and application (Honig WK, ed), pp 565-608. New York: Appleton-Century-Crofts

Timmerman W, Dubocovich ML, Westerink BHC, DeVries JB, Tepper PG, Horn AS (1989) The enantiomers of the dopamine agonist 
$\mathrm{N}-0437$ : in vivo and in vitro effects on the release of striatal dopamine. Eur J Pharmacol 166:1-11.

Van der Zee P, Koger HS, Gootjes J, Hespe W (1980) Aryl 1,4dialk(en)ylpiperazines as selective and very potent inhibitors of DA uptake. Eur J Med Chem Chim Ther 15:363-370.

Weiss F, Markou A, Lorang MT, Koob GF (1992) Basal extracellular DA levels in the NAcc are decreased during cocaine withdrawal after unlimited-access self administration. Brain Res 593:314-318.

Westerink BHC, Tuntler J, Damsma G, Rollema H, De Vries JB (1987) The use of tetrodotoxin for the characterization of drug-enhanced release in conscious rats studied by brain dialysis. Naunyn Schmiedebergs Arch Pharmacol 336:502-507.

Wcstcrink BHC, Hofsteede HM, Damsma G, De Vries JB (1988) The significance of extracellular calcium for the release of DA, acetylcholine and amino acids in conscious rats, evaluated by brain microdialysis. Naunyn Schmiedebergs Arch Pharmacol 337:373-378.

Wise RA (1982) Neuroleptics and operant behavior: the anhedonia hypothesis. Behav Brain Sci 5:39-87.

Wise RA (1987) Intravenous drug self-administration: a special case of positive reinforcement. In: Methods of assessing the reinforcing properties of abused drugs (Bozarth MA, ed), pp 117-141. New York: Springer.

Wise RA (1989) The brain and reward. In: The neuropharmacological basis of reward (Liebman JM, Cooper SJ, eds), pp 377-424. New York: Oxford UP.

Wise RA, Bozarth MA (1987) A psychomotor stimulant theory of addiction. Psychol Rev 94:469-492.

Wise RA, Rompré P-P (1989) Brain DA and reward. Annu Rev Psychol 40:191-225.

Wise RA, Yokel RA, Hansson P, Gerber GJ (1977) Concurrent intracranial self-stimulation and amphetamine self-administration in rats. Pharmacol Biochem Behav 7:459-461.

Wise RA, Spindler J, deWit H, Gerber GJ (1978) Neuroleptic-induced "anhedonia" in rats: pimozide blocks the reward quality of food. Science 201:262-264.
Wise RA, Murray A, Bozarth MA (1990) Bromocriptine self-administration and bromocriptine-reinstatement of cocaine-trained and heroin-trained lever-pressing in rats. Psychopharmacology (Berlin) 100:355-360.

Woodward DJ, Chang JY, Sawyer SR (1992) Electrophysiological recordings of NAcc neuronal activity during a modified FR-3 schedule for cocaine self-administration. Soc Neurosci Abstr 18:1572.

Woolverton WL, Goldberg LI, Ginos J (1984) Intravenous self-administration of DA receptor agonists by rhesus monkeys. J Pharmacol Exp Ther 230:678-683.

Yokel RA (1987) Intravenous self-administration: response rates, the effects of pharmacological challenges, and drug preferences. In: Methods of assessing the reinforcing properties of abused drugs (Bozarth MA, ed), pp 1-33. New York: Springer.

Yokel RA, Pickens R (1973) Self-administration of optical isomers of amphetamine and methylamphetamine by rats. $J$ Pharmacol Exp Ther 187:27-33.

Yokel RA, Pickens R (1974) Drug level of $d$-and $l$-amphetamine during intravenous self-administration. Psychopharmacologia 34:255264.

Yokel RA, Wise RA (1975) Increased lever-pressing for amphetamine after pimozide in rats: implications for a DA theory of reward. Science 187:547-549.

Yokel RA, Wise RA (1976) Attenuation of intravenous amphetamine reinforcement by central DA blockade in rats. Psychopharmacology (Berlin) 48:311-318.

Yokel RA, Wise RA (1978) Amphetamine-type reinforcement by DAergic agonists in the rat. Psychopharmacology (Berlin) 58:289296.

Zetterstrom T, Sharp T, Marsden CA, Ungerstedt U (1983) In vivo measurement of DA and its metabolites by intracerebral dialysis: changes after $d$-amphetamine. J Neurochem 41:1769-1773. 